
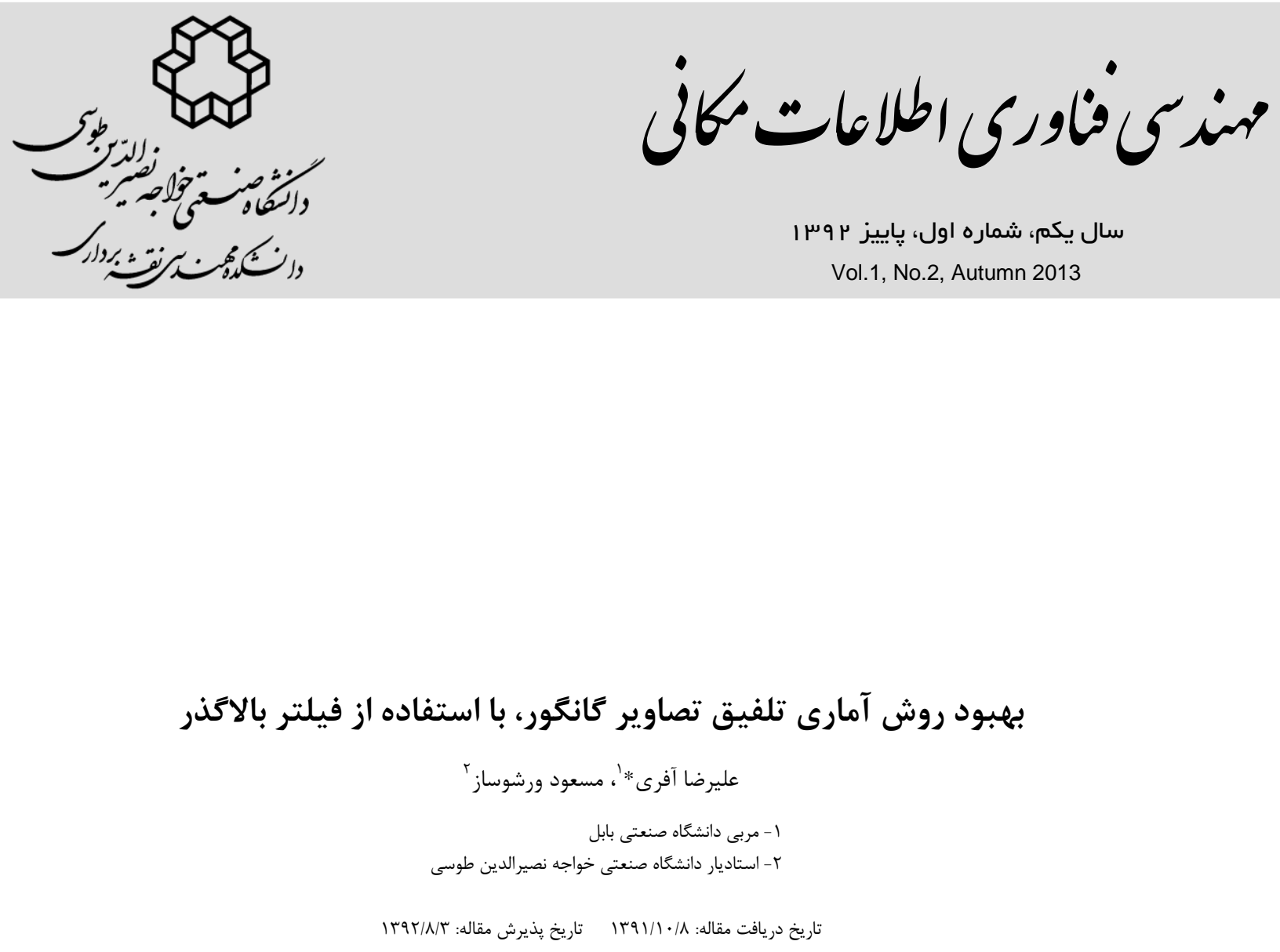

جִكيده

از جمله روشهاى تلفيق تصاوير، استفاده از روشهاى آمارى است كه براساس يارامترهاى آمارى كلى و يا محلى تصاوير مورد اسـتفاده در

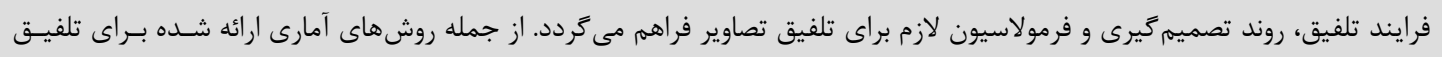

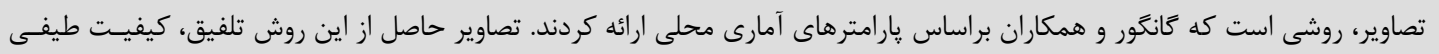

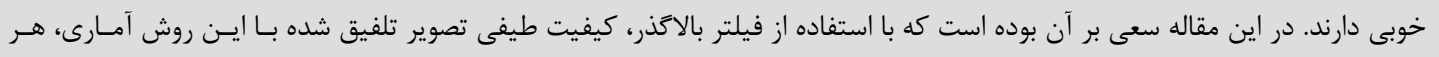

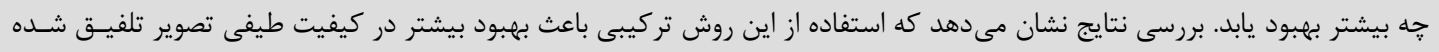

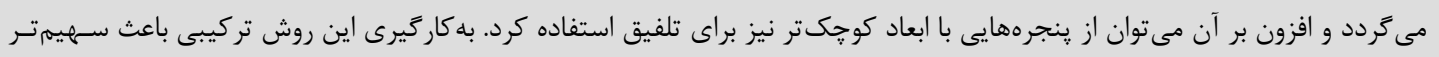

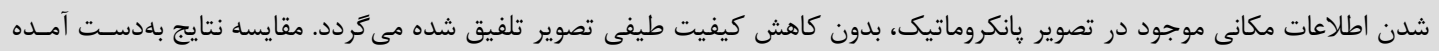

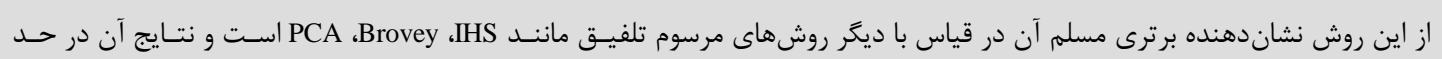
نتايج حاصل از تلفيق با روش تبديل موجك است. كليدوازهها: تلفيق تصاوير، روش آمارى، فيلتر بالاكذر. 
روش كانكور و همكاران [l][ جزو روشهاى آمارى است كه براساس تفسيرهاى طيفـى و مكـانى از يارامترهـاى

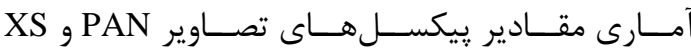

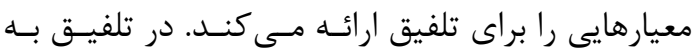
روش كانكَور و همكاران، كل اطلاعـات طيفـى و مكانى إنى موجود در تصوير PAN براى تلفيق به كار مىرود و اين

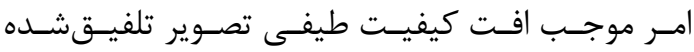

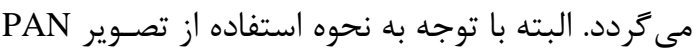

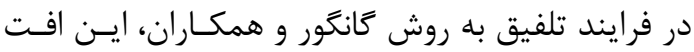

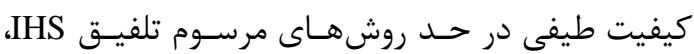
PCA و Brovey

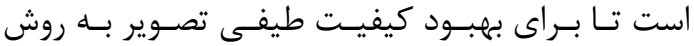

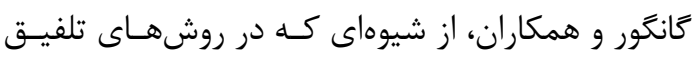

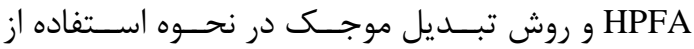
تصوير PAN براى بهبود در كيفيت طيفى تصوير تلفيق شده وجود دارد، بهمنظور تلفيق استفاده گردد. بنابر اين تصني به جاى استفاده از كل اطلاعات طيفى و مكانى موجــود

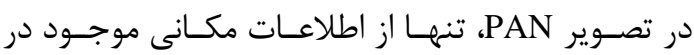

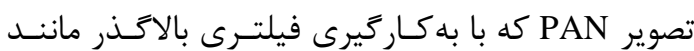

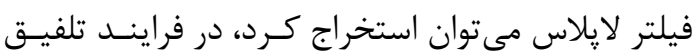
استفاده شده است.

1-1 - دادههاى مورد استفاده و منطقة مورد مطالعه

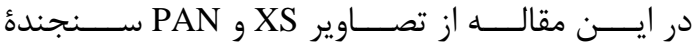

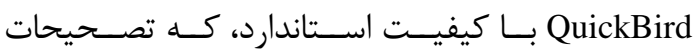
راديومتريك و هندسى بر آنها اعمال شده است، استفاده

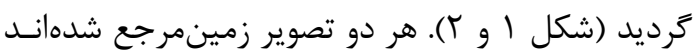

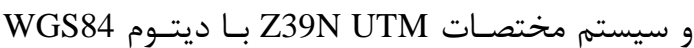
دارند. قدرت تفكيك تصوير PAN در حدود \&m|• است

1. Geo-reference

2. Co-Register

3. Resample

4. Decision Making

5. Intensity-Hue-Saturation

6. Principle Component Analysis

7. Wavelet Transform

8. High-Pass Filter Additive
- 1- - 1قدمه

با بيشرفت سـنجندههـاى موسـوم بـهـ سـنجش از دور، امكانِ گرفتن تصاويرى با قدرت تفكيك مكـانى بـالا، در حد متر و كمتر از متر، فراهم شده اسـت. بـا ايسن حسال هنوز هم به علت محدوديت در امكان ذخيـره و ارسـال

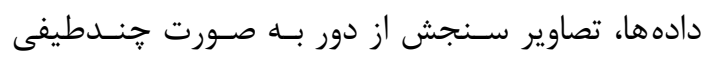
(تصوير XS) و קانكروماتيك (تصوير PAN) و بـا قـدرت تفكيكهاى مكانى متفاوت گرفته مى شوند. مى توان اين محدوديت را بـا اسـتفاده از روشهــاى مختلـف تلفيـقي مئي

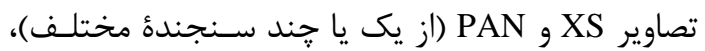
رفع كرد و تصاويرى جندطيفى با قدرت تفكيك مكـانى در حـد تصـاوير PAN بـهدسـت آورد. هــدف از تلفيـق

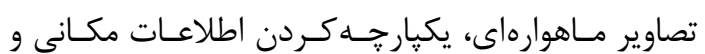

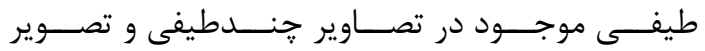
يانكروماتيك با قدرت تفكيك مكانى بالا و نيـز افـزايش

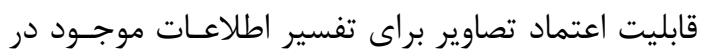
آنهاست و محصول نهايى بايد همانند تصويرى باشد كـه كه

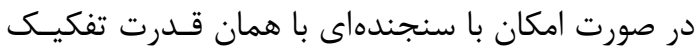
طيفى و مكانى تـوأم تصـاوير XS و PAN

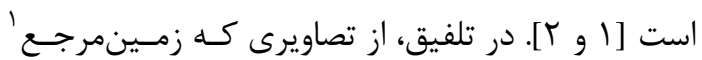
شدهاند و يا دست كم با يكديخر همنتخاشت لانـد اسـتفاده

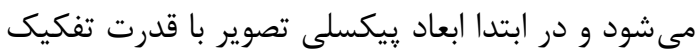
يايين (تصوير XS) به ابعاد تصوير با قدرت تفكيـك بـالا

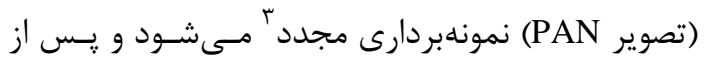
آن عمليات تلفيق بر روى اين تصاوير اجراشدنى خواهد ندردي بود.

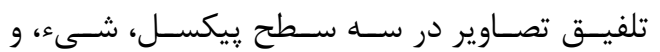

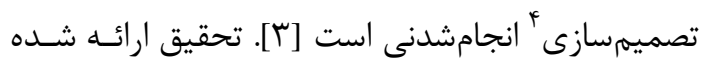

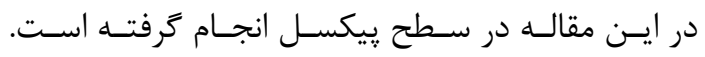
روشهاى مبتنى بر ريكسل را نيز مى توان به روشهـاى

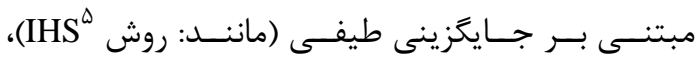

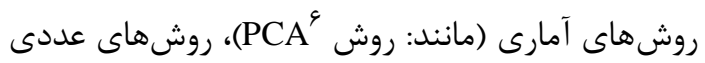

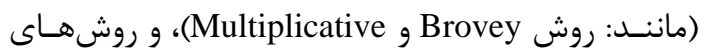

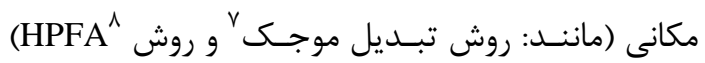
تقسيم كرد [r]. 


\section{r- روشهاى متداول در تلفيق تصاوير

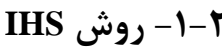

روش IHS درواقـع روش جـايكزينى طيفـى محسـوب

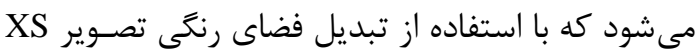
از فضاى RGB به فضاى IHS و جايكز ينى مؤلفعٔ مكانى

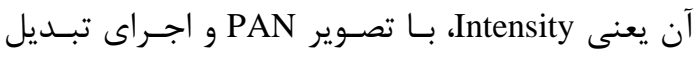

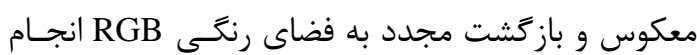

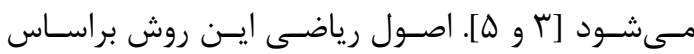

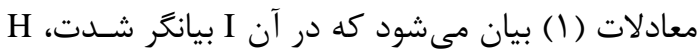

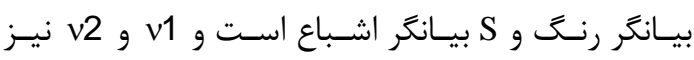
متغيرهاى واسطه مورد نياز براى تبديلانـد [ب]. تصـوير تلفيق شده با روش HIS، در شكل ب ديده مىشود.

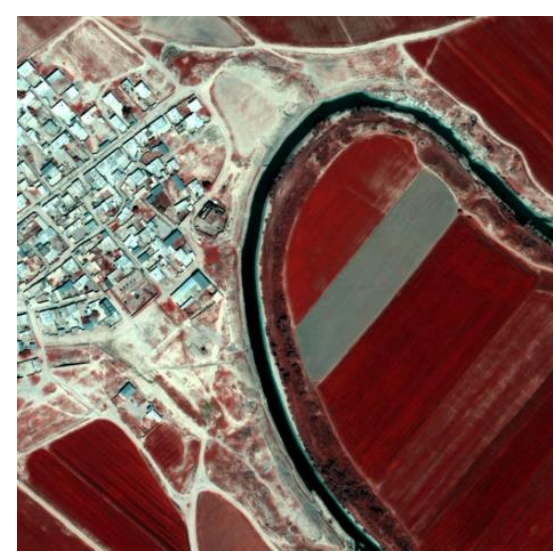

شكل r. تصوير تلفيقشده با روش IHS

\section{BROVEY روش-r}

روش Brovey درواقع روشـى عـددى اسـت كـه در آن آن

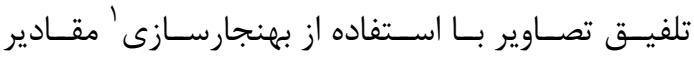

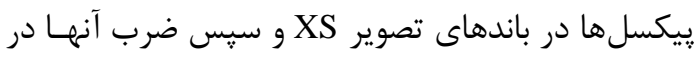
مقـدار يِيكسـلهــاى متنــاظر در تصـوير PAN انجـام

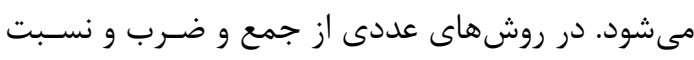
بين باندهاى مختلف تصوير XS و تصوير PAN استفاد ودي مى شود. الكَوريتم روش Brovey براى تلفيـق تصـويرى تصوي

1. Normalizing
كه در محدودة طيفى نور مرئى و مـادون قرمـز نزديـك

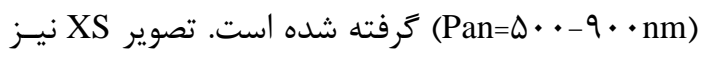
داراى قدرت تفكيك مكـانى r/Fm اسـت كـه در جهــار بانـــد طيفــى آبــى (Blue=fD.

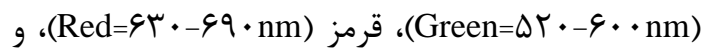

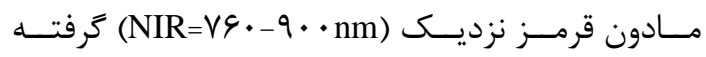
شدهاند. منطقه مورد مطالعه در مرودشت و در نزديكى فردى فردي

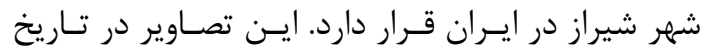

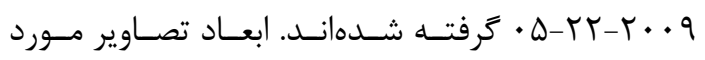

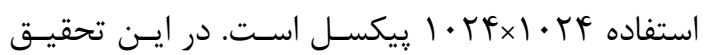
براى ايجاد يكنواختى در نتايج روشهاى مختلف تلفيق

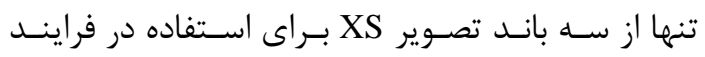

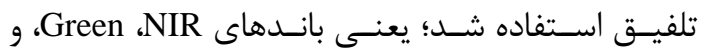

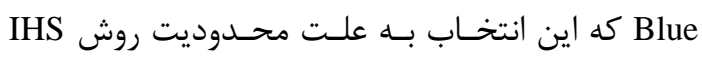
(استفاده از تنها سه باند) براى تلفيق انجام شده است.

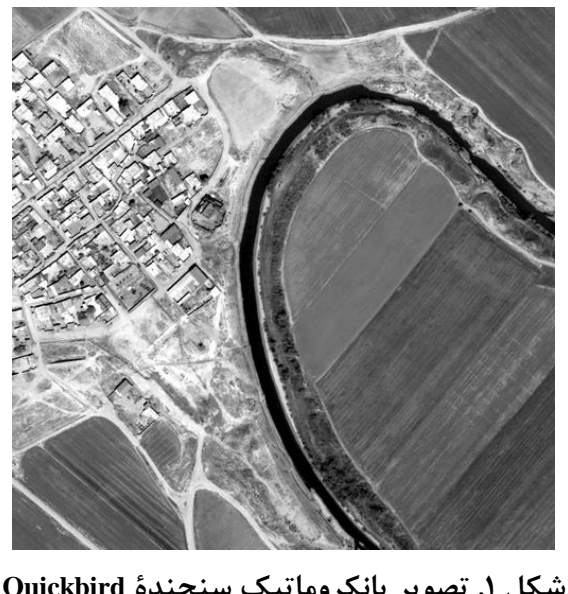

شكل 1. تصوير پانكروماتيك سنجنده Quickbird

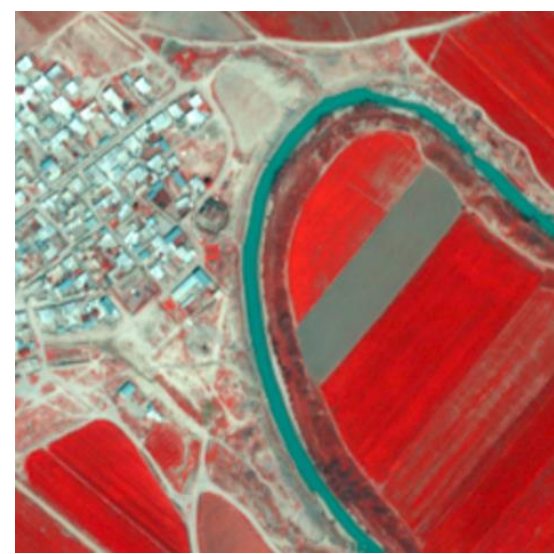

شكل r. تركيب رنكى مجازى از سه باند تصوير جندطيفى QuickBird 
رابطه (r)

$D N_{i}^{\text {Fissed }}=\frac{D N_{X S i}}{D N_{X S 1}+D N_{X S 2}+\ldots+D N_{X S n}} D N_{P A N}$

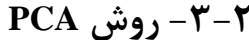

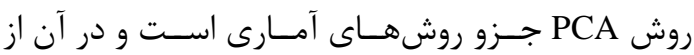
تبديل خطى براى انتقال و دوران باندهاى تصوير XS به سيستم مختصـات تـازه بــا بيشـترين واريـانس ممكـن استفاده مىشود. تبديل PCA براى استخراج متغيرهاى مستقل از يكديگر، باندهاى مستقل از متغيرهاى وابسته يا همان بانـدهاى تصـوير XS و جـايكز ينى اولـين بانـــ تبديل PCA با تصوير PAN و اجـراى تبـديل معكـوس بـراى تلفيـق اسـتفاده مسىشـود [ـ و 9]. در شـكل ه، تصوير تلفيق شده با روش PCA نشان داده شده است.

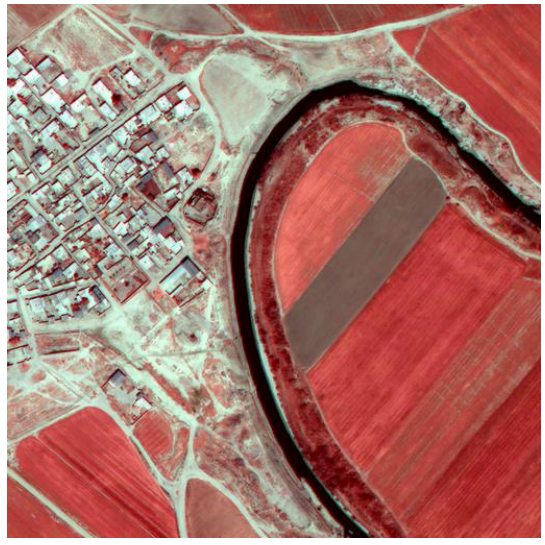

شكل ه. تصوير تلفيق شده با روش PCA

HPFA روش

روش HPFA را نخستين بار در سال • •919 1، شـوونكردك

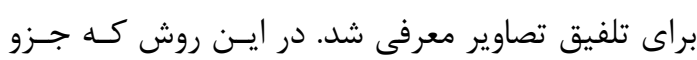

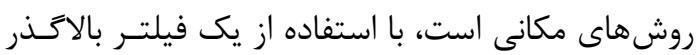

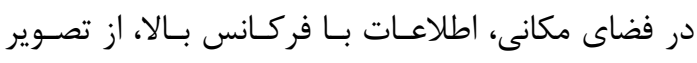
PAN استخراج مىشود و به باندهاى تصوير XS افـزوده

$$
\text { مى تردد [V] }
$$

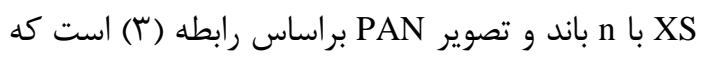

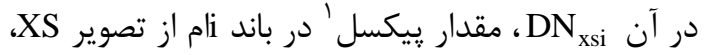

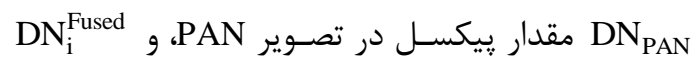
مقدار يیكسل در تصوير تلفيقشده در باند متناظر با أمام

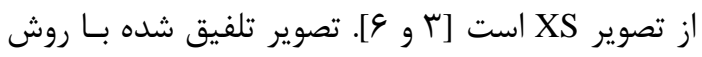
Brovey

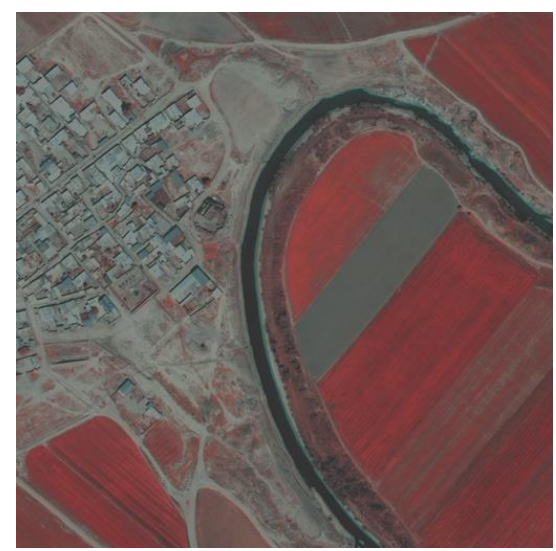

شكل F. تصوير تلفيق شده با روش Brovey

$\left[\begin{array}{l}I \\ v_{1} \\ v_{2}\end{array}\right]=\left[\begin{array}{ccc}\frac{1}{\sqrt{3}} & \frac{1}{\sqrt{3}} & \frac{1}{\sqrt{3}} \\ \frac{1}{\sqrt{6}} & \frac{1}{\sqrt{6}} & -\frac{2}{\sqrt{6}} \\ \frac{1}{\sqrt{6}} & -\frac{2}{\sqrt{6}} & 0\end{array}\right]\left[\begin{array}{l}R \\ G \\ B\end{array}\right]$

رابطه (1)

$$
H=\tan ^{-1}\left(\frac{v_{2}}{v_{1}}\right) ; \quad S=\sqrt{v_{1}^{2}+v_{2}^{2}}
$$

$\left[\begin{array}{l}R \\ G \\ B\end{array}\right]=\left[\begin{array}{ccc}\frac{1}{\sqrt{3}} & \frac{1}{\sqrt{6}} & \frac{1}{\sqrt{2}} \\ \frac{1}{\sqrt{3}} & \frac{1}{\sqrt{6}} & -\frac{1}{\sqrt{2}} \\ \frac{1}{\sqrt{3}} & -\frac{2}{\sqrt{6}} & 0\end{array}\right]\left[\begin{array}{l}I \\ v_{1} \\ v_{2}\end{array}\right] \quad(r)$ (ابط)

1. Digital Number

2. Schowengerd 
خــوردن محتـواى طيفى تصـوير حاصـل از تلفيـق بــهـ

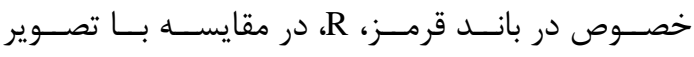

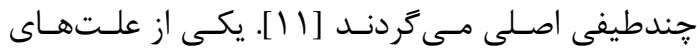

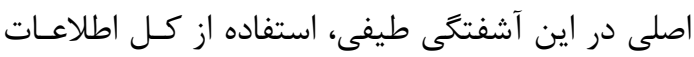

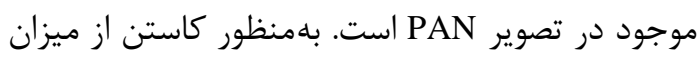

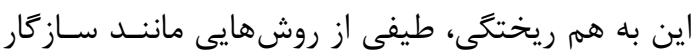

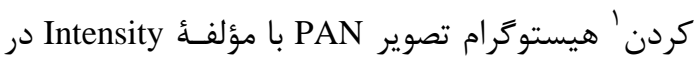

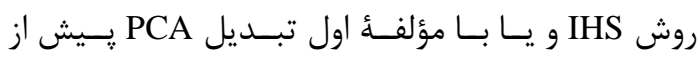

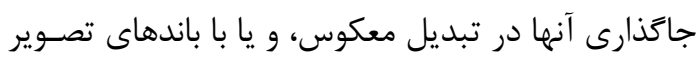
XS ييش از ضرب آن در مقادير بهنجارشدة تصوير XS

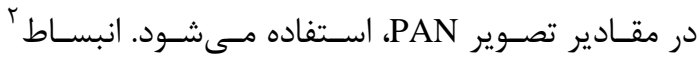

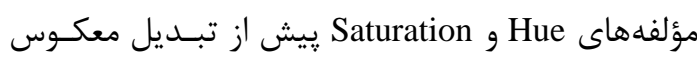

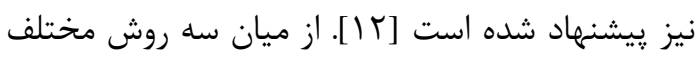
محاسبة Intensity در تبديل IHS، محاسبة آن براساس I=( به نتايج بهترى منجر مسى تحردد

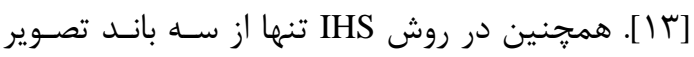

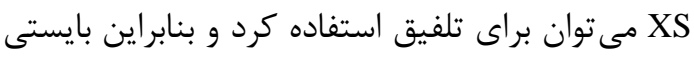

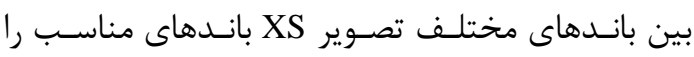

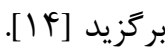

در روش PCA كيفيت طيفـى تصـوير تلفيـق شـده

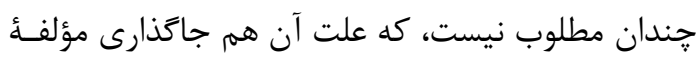

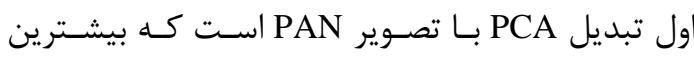
واريـانس را دارد. ايـن جـايكز ينى باعـث افـزايش تـأثير تصوير PAN بر روى تصوير تلفيق شده مى خردد.

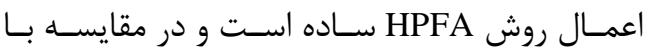
روش IHS، Brovey و PCA، به علـت اسـتفاده از تنهـا اطلاعات مكانى موجود در تصوير PAN، محتواى طيفى

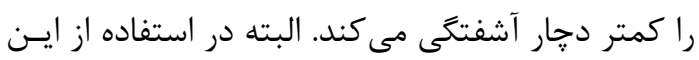

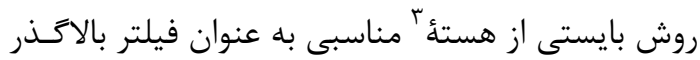

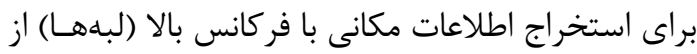

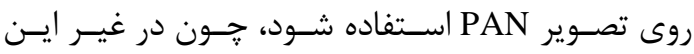

1. Histogram Matching

2. Stretch

3. Kernel

\section{ك-ه - روش تبديل موجك}

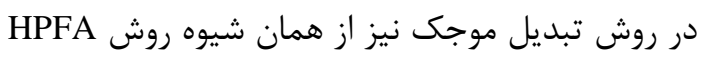

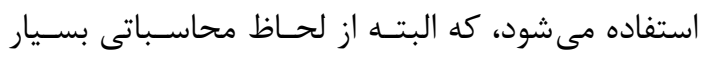

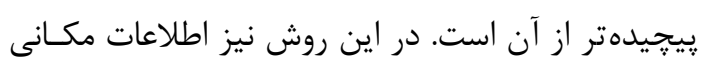

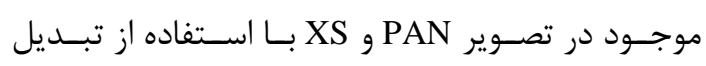

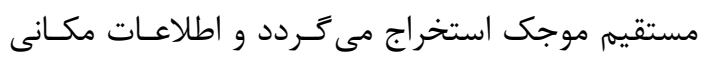

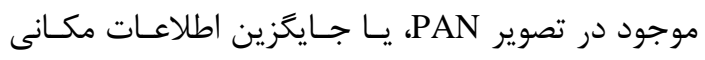

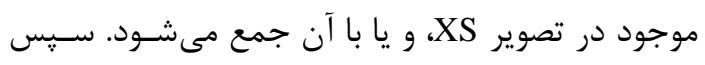

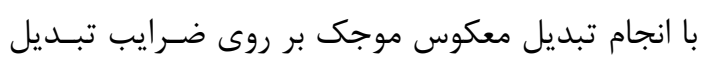

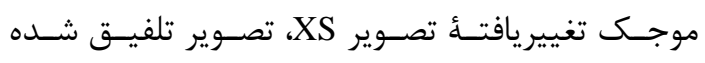

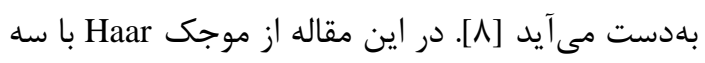

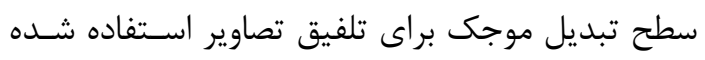

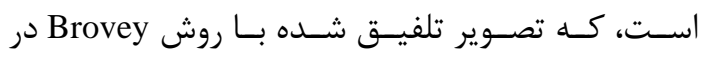
شكل 9 ديده مىشود.

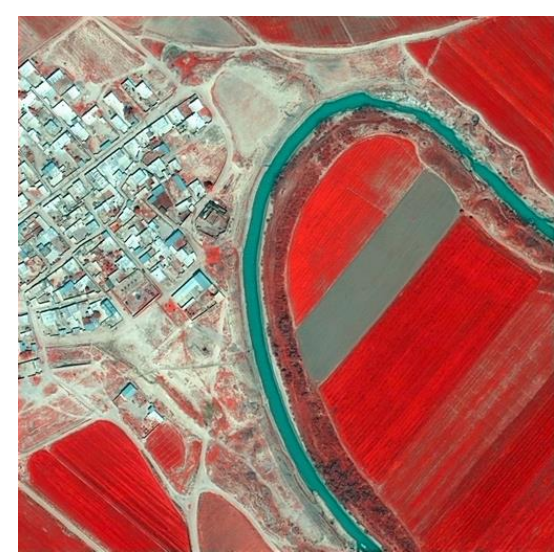

شكل 9. تصوير تلفيق شده با روش Wavelet

\section{r-4- مزايا و كاستىهاى روشهاى مرسوم}

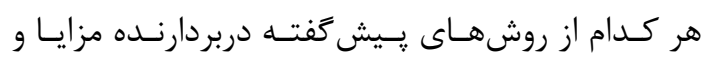

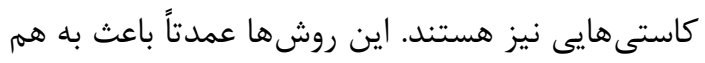

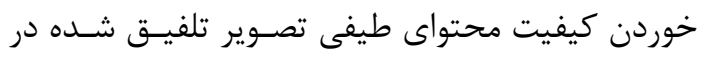

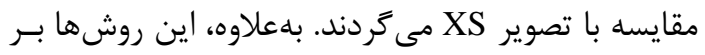

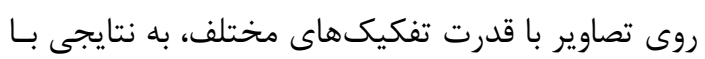

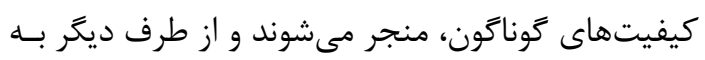

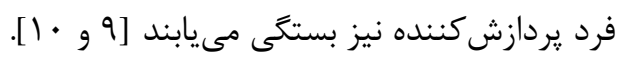

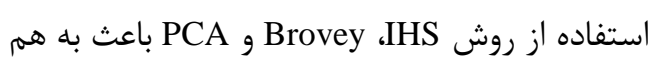


$\mathrm{F}_{\mathrm{i}, \mathrm{j}}^{\mathrm{k}}=\mathrm{a}_{\mathrm{i}, \mathrm{j}}^{\mathrm{k}} \times \mathrm{P}_{\mathrm{i}, \mathrm{j}}+\mathrm{b}_{\mathrm{i}, \mathrm{j}}^{\mathrm{k}} \times X \mathrm{XS}_{\mathrm{i}, \mathrm{j}}^{\mathrm{k}}$

$\mathrm{k}=1,2 \ldots, \mathrm{N}$

رابطه (F)

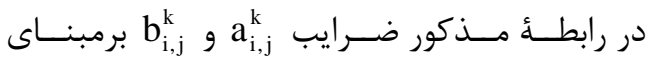

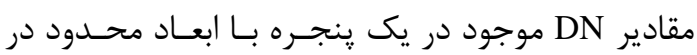

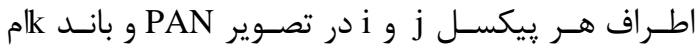

تصوير XS تعريف مى كردنـد و براسـاس روابـط آمـارى محاسبه مى شوند. ميانگين هر ي يكسل در تصوير تلفيق شده به ترتيب با استفاده از اعمال عملكر اميد رياضى E(X) و قانون انتشار ميانگَين

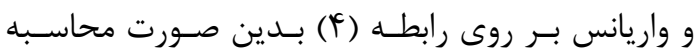

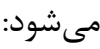

$$
\begin{aligned}
& E\left(F_{i, j}^{k}\right)=E\left(a_{i, j}^{k} \times P_{i, j}+b_{i, j}^{k} \times X S_{i, j}^{k}\right) \\
& \mu_{F_{i, j}^{k}}=a_{i, j}^{k} \times \mu_{P_{i, j}}+b_{i, j}^{k} \times \mu_{X S_{i, j}^{k}}^{k}
\end{aligned}
$$

(9) (9)

$\operatorname{cov}\left(P_{i, j}^{k}, X S_{i, j}^{k}\right)=\left[\begin{array}{cc}\sigma_{P_{i, j}^{k}}^{2} & \sigma_{P_{i, j}^{k}, X S_{i, j}^{k}} \\ \sigma_{P_{i, j}^{k}, X S_{i, j}^{k}}^{k} & \sigma_{X S_{i, j}^{k}}^{2}\end{array}\right]$

(V) رابطه

$$
\begin{aligned}
& \sigma_{\mathrm{F}_{i, j}^{k}}^{2}=\left[\begin{array}{ll}
\mathrm{a}_{\mathrm{i}, \mathrm{j}}^{\mathrm{k}} & \mathrm{b}_{\mathrm{i}, \mathrm{j}}^{\mathrm{k}}
\end{array}\right] \times \operatorname{cov}\left(\mathrm{P}_{\mathrm{i}, \mathrm{j}}^{\mathrm{k}}, \mathrm{XS}_{\mathrm{i}, \mathrm{j}}^{\mathrm{k}}\right) \times\left[\begin{array}{c}
\mathrm{a}_{\mathrm{i}, \mathrm{j}}^{\mathrm{k}} \\
\mathrm{b}_{\mathrm{i}, \mathrm{j}}^{\mathrm{k}}
\end{array}\right] \\
& =\left(\mathrm{a}_{\mathrm{i}, \mathrm{j}}^{\mathrm{k}}\right)^{2} \times \sigma_{\mathrm{P}_{\mathrm{i}, \mathrm{j}}^{\mathrm{k}}}^{2}+ \\
& 2 \times \mathrm{a}_{\mathrm{i}, \mathrm{j}}^{\mathrm{k}} \times \mathrm{b}_{\mathrm{i}, \mathrm{j}}^{\mathrm{k}} \times \sigma_{\mathrm{P}_{\mathrm{i}, \mathrm{j}}^{\mathrm{k}} \times \mathrm{SS}_{\mathrm{i}, \mathrm{j}}^{\mathrm{k}}}+\left(\mathrm{b}_{\mathrm{i}, \mathrm{j}}^{\mathrm{k}}\right)^{2} \times \sigma_{\mathrm{XS} \mathrm{S}_{\mathrm{i}, \mathrm{j}}^{\mathrm{k}}}^{2}
\end{aligned}
$$

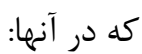

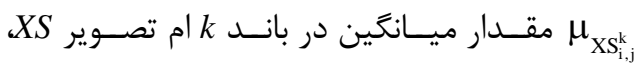

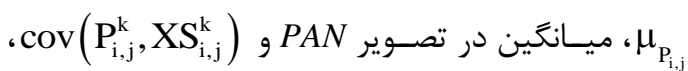

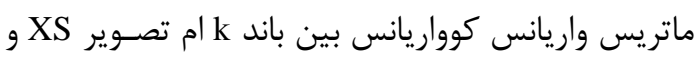
تصوير PAN هستند.

تصوير بهدست آمده از تلفيـق تصـاوير XS و PAN،

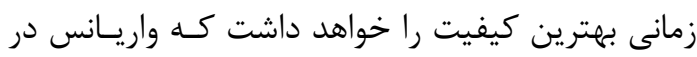
هر باند تصوير تلفيق شده برابـر بـا واريـانس در تصـوير

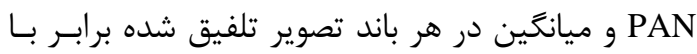

صورت كيفيت محتواى طيفى تصوير تلفيق شده در اين

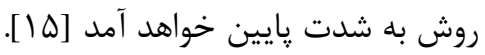

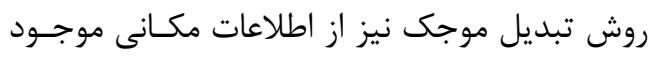
در تصوير PAN براى تلفيق استفاده مىشـود و تصـاوير

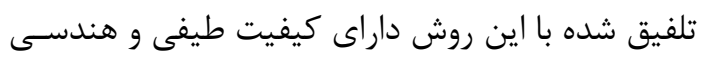
بسيار خوبى هستند ولى به لحاظ محاسباتى سنَيناند.

\section{r- روش آمارى تلفيق تصاوير}

روش استفاده شده در اين تحقيق براى تلفيـق تصـاوير، آماوير

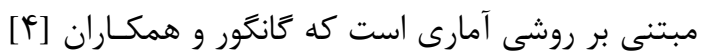

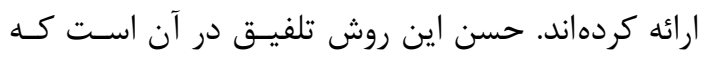

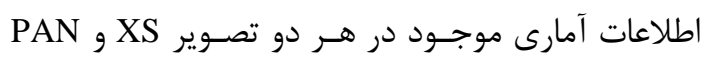
براى ايجاد تصوير تلفيق شده به كار مسىرود. همجنسين

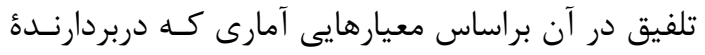

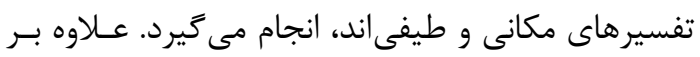

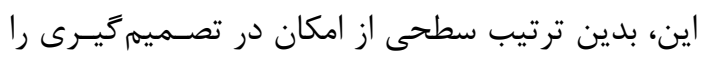
براى كاربر در محاسبه يارامترهاى آمارى فراهم مي كندي إندا.

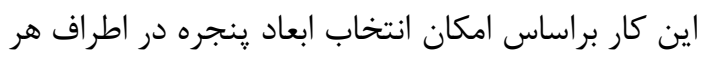

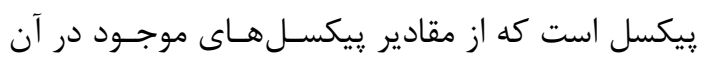

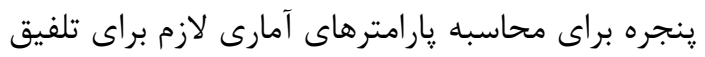

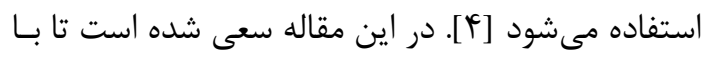

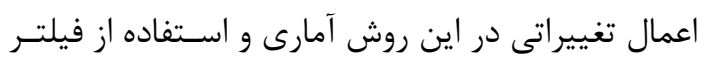

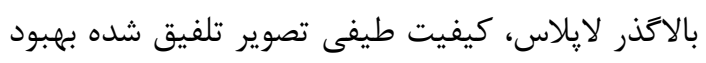

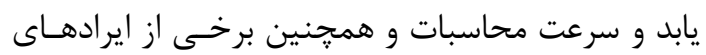

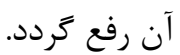

\section{r-1- إد مواد ورشها}

براى تلفيق تصاوير PAN و XS مى Xــــان از ايجـاد يـك

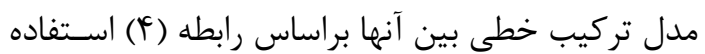

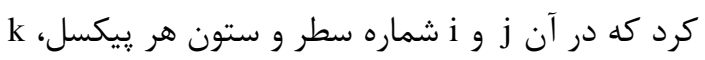

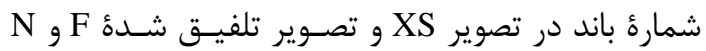

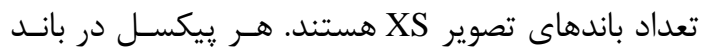

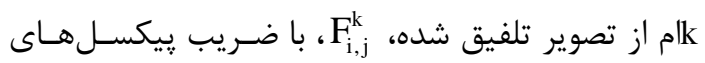

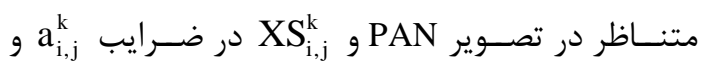
محاسبه خواهد شد. bu bi,j 


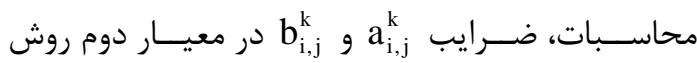

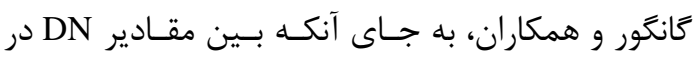

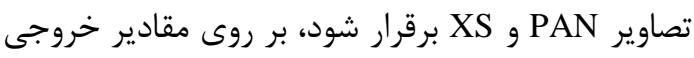
حاصل از اعمال يك فيلتر بالاكذر بر روى تصاوير PAN

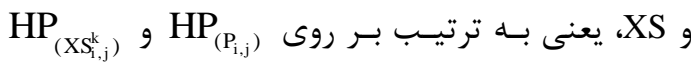

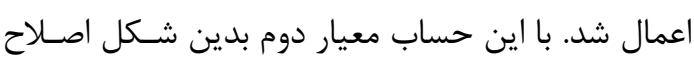
گرديد:

معيار دوم اصلاحشده: واريانس خروجى حاصـل از

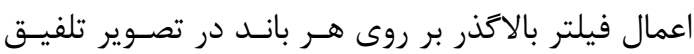

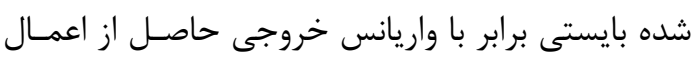
فيلتر بالاحذر بر روى تصوير PAN باشد.

$$
\begin{aligned}
& \sigma_{\mathrm{HP}_{\left(\mathrm{f}_{\mathrm{k}}^{\mathrm{k}} \mathrm{j}\right.}}^{2}=\left(\mathrm{a}_{\mathrm{i}, \mathrm{j}}^{\mathrm{k}}\right)^{2} \times \sigma_{\mathrm{HP}_{\left(\mathrm{P}_{\mathrm{i}, \mathrm{j}}\right)}^{2}}^{2}
\end{aligned}
$$

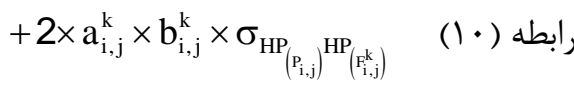

$$
\begin{aligned}
& +\left(\mathrm{b}_{\mathrm{i}, \mathrm{j}}^{\mathrm{k}}\right)^{2} \times \sigma_{\mathrm{HP}_{\left(\mathrm{Ss}_{\mathrm{i}, \mathrm{j}}^{\mathrm{k}}\right)}}^{2}=\sigma_{\mathrm{HP}_{\left(\mathrm{P}_{\mathrm{i}, \mathrm{j}}\right)}^{2}}^{2}
\end{aligned}
$$

انجام اين تغيير در معيـار دوم، بــا توجـهـ بـهـ اينكـهـ

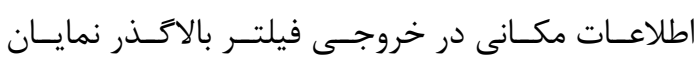

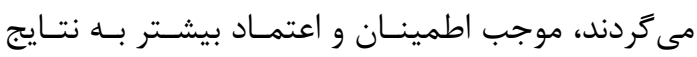

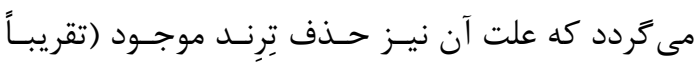

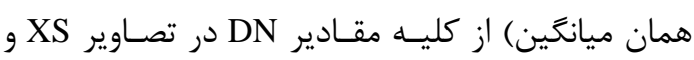
PAN براى محاسبهُ ضرايب

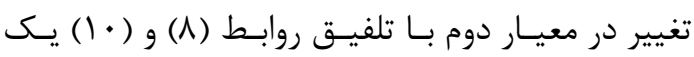

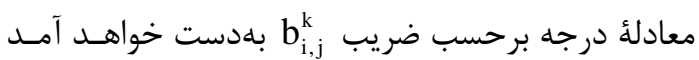

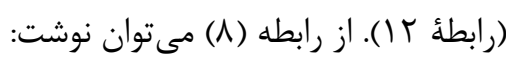

رابطه (1)

$$
\begin{aligned}
& \mathrm{a}_{\mathrm{i}, \mathrm{j}}^{\mathrm{k}}=\frac{\mu_{\mathrm{XS}_{\mathrm{i}, \mathrm{j}}^{\mathrm{k}}}}{\mu_{\mathrm{P}_{\mathrm{i}, j}}} \times\left(1-\mathrm{b}_{\mathrm{i}, \mathrm{j}}^{\mathrm{k}}\right)=\mathrm{M} \times\left(1-\mathrm{b}_{\mathrm{i}, \mathrm{j}}^{\mathrm{k}}\right) \\
& \mathrm{M}=\frac{\mu_{\mathrm{XS} \mathrm{i}, \mathrm{j}}}{\mu_{\mathrm{P}_{\mathrm{i}, j}}}
\end{aligned}
$$

با جاكذارى ضريب a از ابطه (^) در رابطه (V)،

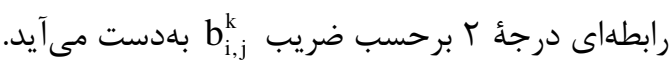

ميانكَين باند متناظر آن در تصـوير XS باشــــ بنـابراين

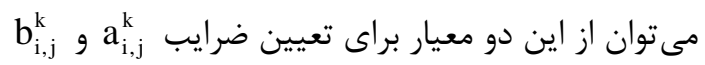

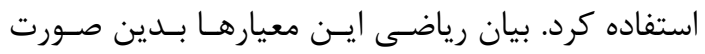
معيار اول: ميانكين هر باند در تصـوير تلفيـق شـده

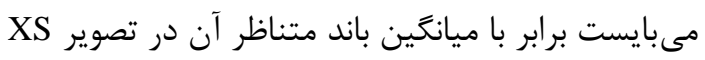
باشد. $\mu_{\mathrm{F}_{i, j}^{k}}=\mathrm{a}_{\mathrm{i}, \mathrm{j}}^{\mathrm{k}} \times \mu_{\mathrm{P}_{\mathrm{i}, j}}+\mathrm{b}_{\mathrm{i}, \mathrm{j}}^{\mathrm{k}} \times \mu_{\mathrm{XS}_{\mathrm{i}, \mathrm{j}}^{\mathrm{k}}}=\mu_{\mathrm{XS}_{\mathrm{i}, \mathrm{j}}^{\mathrm{k}}} \quad($ () معيار دوم: واريانس هر باند در تصوير تلفيـق شـده برابر با واريانس تصوير PAN باشد.

$$
\begin{aligned}
\sigma_{\mathrm{F}_{i, j}^{k}}^{2}= & \left(\mathrm{a}_{\mathrm{i}, \mathrm{j}}^{\mathrm{k}}\right)^{2} \sigma_{\mathrm{P}_{\mathrm{i}, \mathrm{j}}^{\mathrm{k}}}^{2}+2 \times \mathrm{a}_{\mathrm{i}, \mathrm{j}}^{\mathrm{k}} \times \mathrm{b}_{\mathrm{i}, \mathrm{j}}^{\mathrm{k}} \\
& +\left(\mathrm{b}_{\mathrm{i}, \mathrm{j}}^{\mathrm{k}}\right)^{2} \sigma_{\mathrm{XS}_{\mathrm{i}, \mathrm{j}}^{\mathrm{k}}}^{2}=\sigma_{\mathrm{P}_{\mathrm{i}, \mathrm{j}}^{\mathrm{k}}}^{2}
\end{aligned}
$$

تصوير تلفيق شده با روش آمارى كانكَور و همكاران در شكل V ديده مىشود.

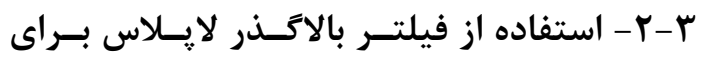
بهبود در روش آمارى تانغور و همكاران بهلطور كلى استفاده از تمامى اطلاعات طيفـى و مكـانى

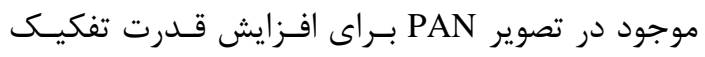

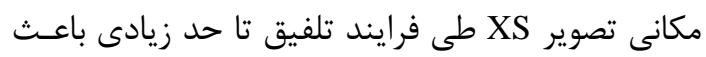

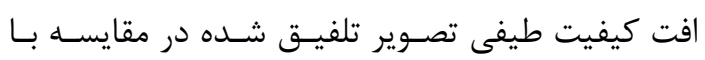

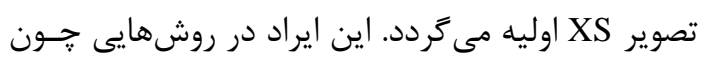

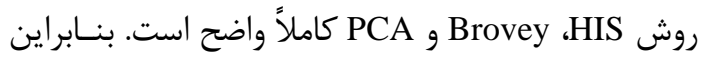

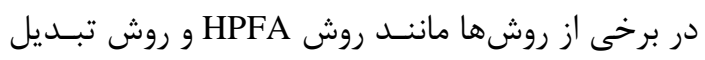

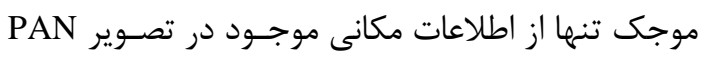

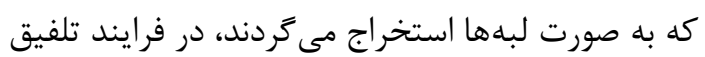

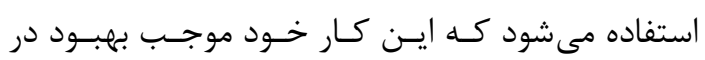

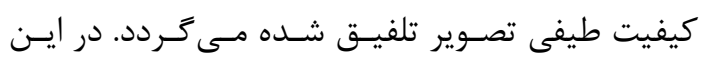

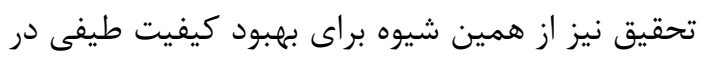
تصوير تلفيق شده به روش كانكور و همكاران، اسـتفاده ندان شده است. بدين ترتيب بــراى ايجـاد بهبــود در كيفيـت نتـايج 
براى اين كار استفاده شـده اسـت [91]. در سـادهتـرين

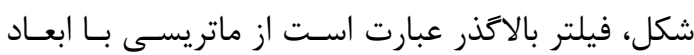

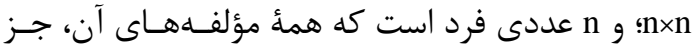

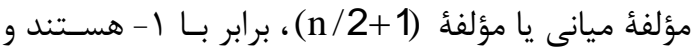

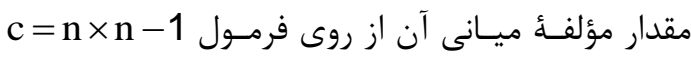

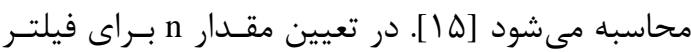
بالاكذر از نسبت بين قدرت تفكيك مكانى تصوير XS و

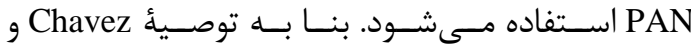

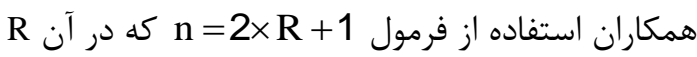

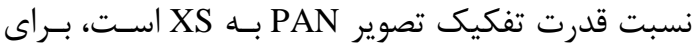

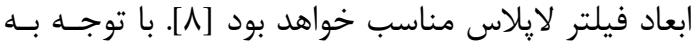

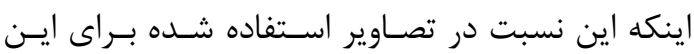
تحقيق برابر R=4 است، ابعـاد فيلتـر مـورد اسـتفاده 9×9 انتخاب شد. افزون بر آن، بهمنظور بهبود كيفيـت آنست

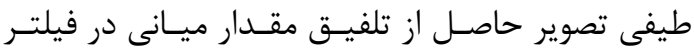

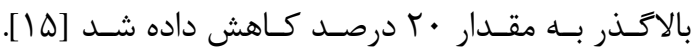

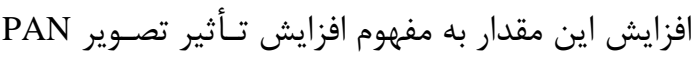
در تصوير تلفيق شده است.

F- بر رسى كيفيت تصاوير تلفيقشده

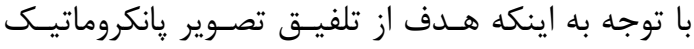

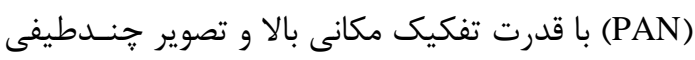

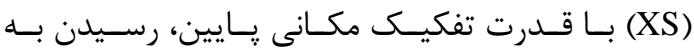
تصويرى קندطيفى با قـدرت تفكيــ مكـانى بالاسـت. بهطور معمول در بررسى كيفيت طيفى تصـاوير تلفيـق

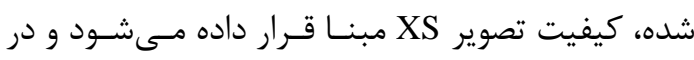
بررسى كيفيت هندسى تصوير تلفيق شده نيـز كيفيـت تصوير PAN مبناى قضاوت خواهد بـود. در ايـن مقالـه تنها كيفيت طيفى تصاوير تلفيق شده مورد بررسى قرئ قرار كرفت و بـراى بررسى از شـاخصهـائيى آمـارى كـهـ در

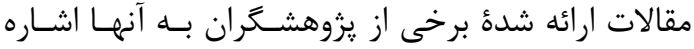

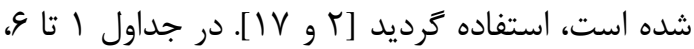

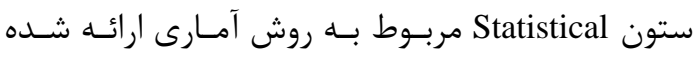

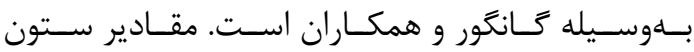

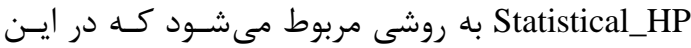

رابطه (T)

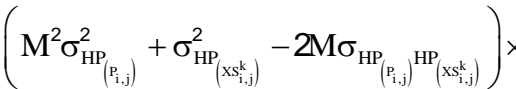

$$
\begin{aligned}
& \left(b_{i, j}^{k}\right)^{2}+\left(2 M \sigma_{H_{\left(p_{i, j}\right)}} H_{\left(x s_{i, j}^{k}\right)}-2 M^{2} \sigma_{\mathrm{HP}_{\left(p_{i, j}\right)}^{2}}^{2}\right) b_{i, j}^{k}+ \\
& \left(\mathrm{M}^{2}-1\right) \sigma_{\mathrm{HP}_{\left(\mathrm{p}_{\mathrm{i}, j}\right)}}^{2}=0
\end{aligned}
$$

از حل اين معادله درجه r، دو جواب بـراى ضـريب

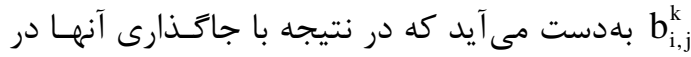

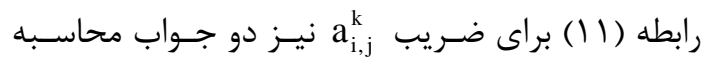

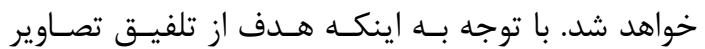

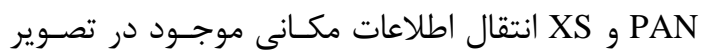

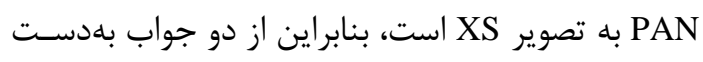

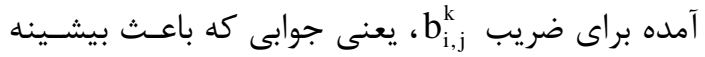

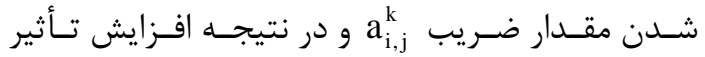
تصوير PAN مى گردد، براى استفاده در تلفيـق انتخـاب

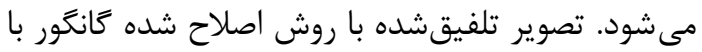

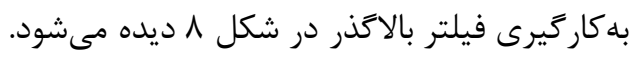

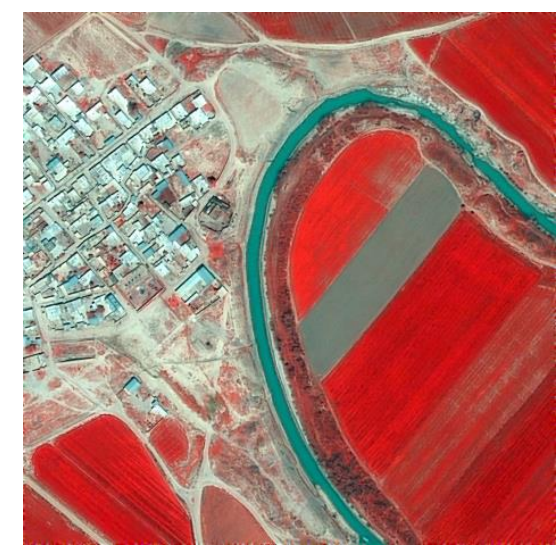

شكل ^. تصوير تلفيق شده با روش اصلاح شده گَانگَور

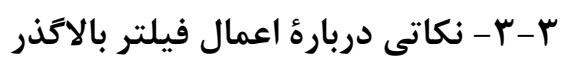

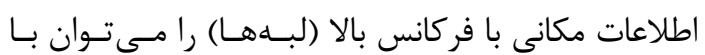

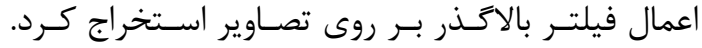

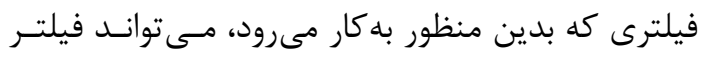

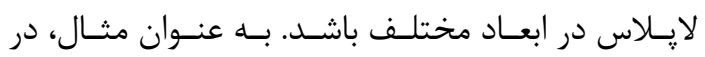

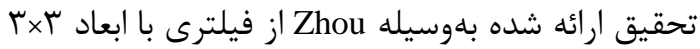




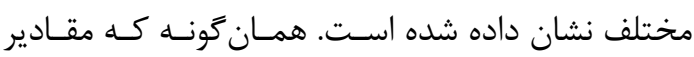
جدول ا نشـان مسىدهنـد، تغييـرات مقــادير ميـانگين

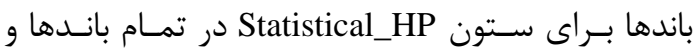

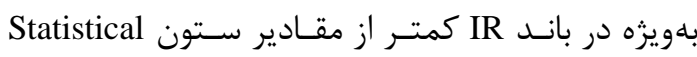

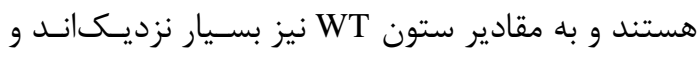

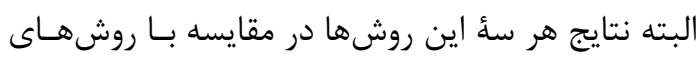

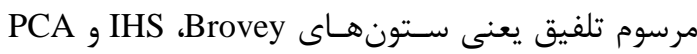

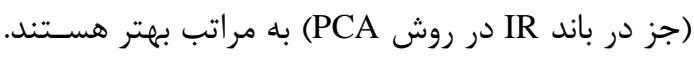

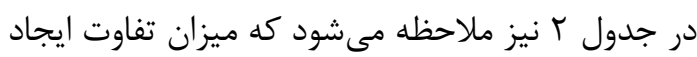

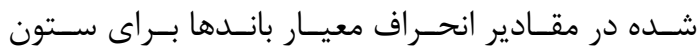

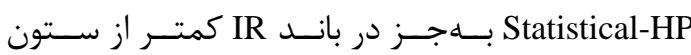
Statistical مقادير سـتون WT همخـوانى بسـيارى دارنــــ در بــين

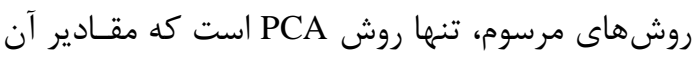

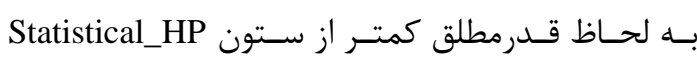

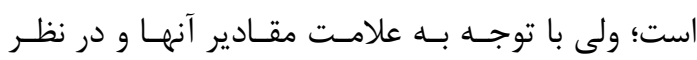

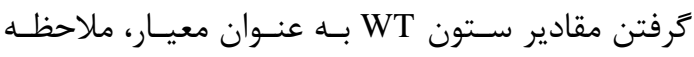

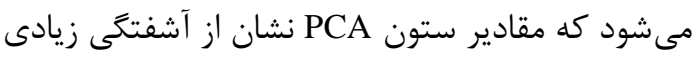

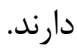

\section{Y-Y-Y-Y همبستغى بين باندهاى تصوير}

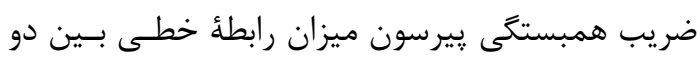

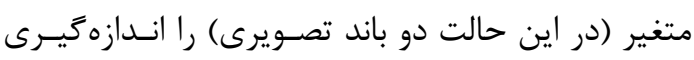
مى كند. مقدار اين شاخص بسين ا-و و ا+نوسـان دارد و

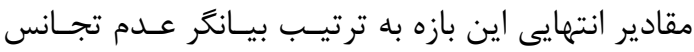

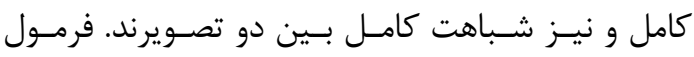

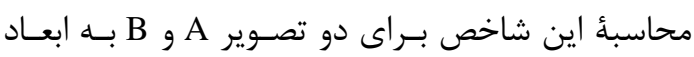

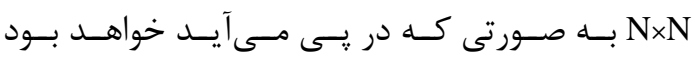

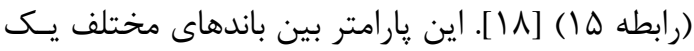

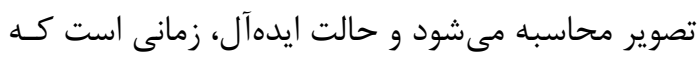

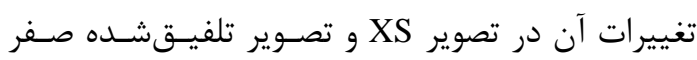
باشد. با توجه به اينكه تصوير XS استفاده شده داراى بـ تصن

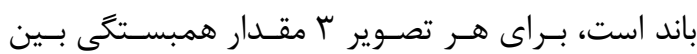

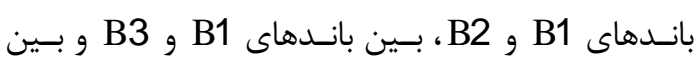
باندهاى B2 و B3 و B B محاسبه ترديد.
مقاله با اعمال تغييــر در معيـار دوم روش كَانكور ارائهـ

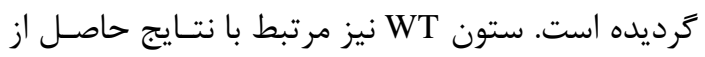

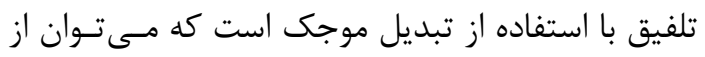

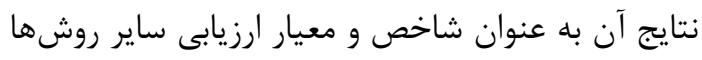

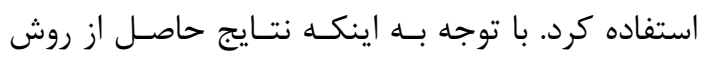
تلفيق با استفاده از تبديل موجك داراى كيفيت بـالايى

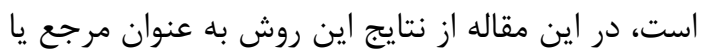

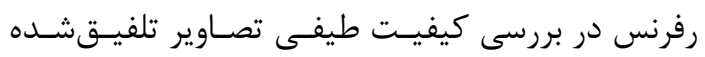

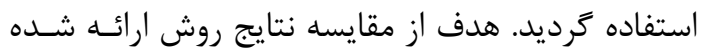
در ايسن تحقيـق بـا روش تبـديل موجـك، نشـان دادن كيفيت مطلوب روش ويشنهادي تحقيق حاضر است.

\section{| - أ بر رسى كيفيت طيفى}

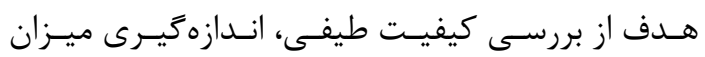

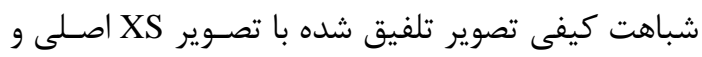

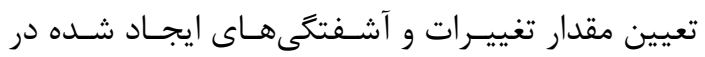

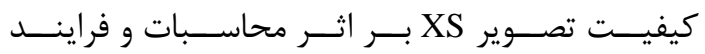

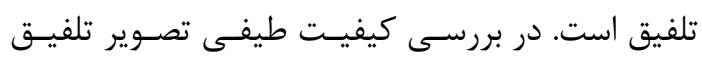

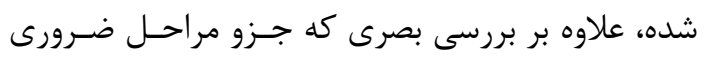

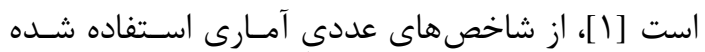

\section{F-1-1-1- تفاوت در مقدار ميانگين و انحراف معيار} تفاوت در مقدار ميـانكين و انحـراف معيـار (بـهـ ترتيـب

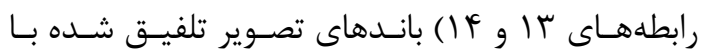

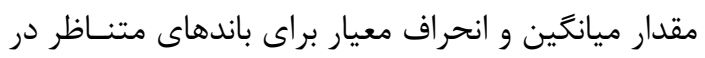
تصوير XS، از جمله شاخصهاى آمارى عددى كيفيـت طيفى تصوير تلفيق شدهاند.

$$
\begin{array}{ll}
\Delta \mu_{\mathrm{Bi}}=\mu\left(\mathrm{MS}_{\mathrm{Bi}}\right)-\mu\left(\mathrm{F}_{\mathrm{Bi}}\right) & \text { رابطه (I ) رابطه (I) }
\end{array}
$$

هر قدر اين تفاوتها كمتر و به مقدار صفر نزديكتر

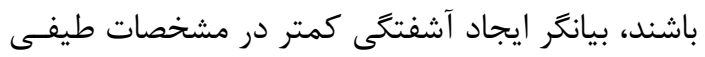

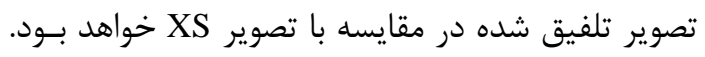

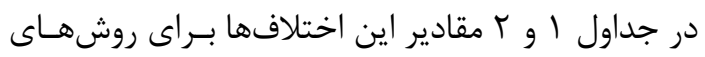


همانطور كه ملاحظه مىشود، روش هاى مرسـوم تنهــا

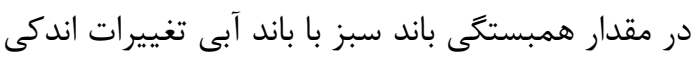

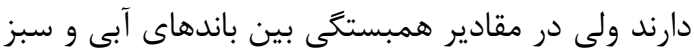

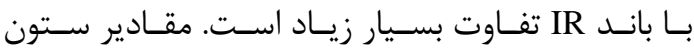

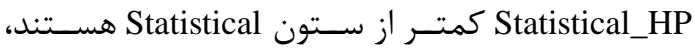
يعنى مقادير همبستتى تغيير كمترى يافتهاند و مقادير

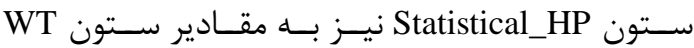
نزديكترند.
رابطه (ه)

$\operatorname{Corr}(\mathrm{A}, \mathrm{B})=$

$$
=\frac{\sum_{i=1}^{N} \sum_{j=1}^{N}\left(A_{i, j}-\bar{A}\right)\left(B_{i, j}-\bar{B}\right)}{\sqrt{\sum_{i=1}^{N} \sum_{j=1}^{N}\left(A_{i, j}-\bar{A}\right)^{2} \sum_{i=1}^{N} \sum_{j=1}^{N}\left(B_{i, j}-\bar{B}\right)^{2}}}
$$

جدول ب ميزان تغييـرات مقـادير همبسـتخى بـين باندهاى تصـاوير تلفيـق شـده را در مقايسـه بـا مقــادير همبستخى بين باندهاى تصوير XS اصلى نشان مى بدهد.

جدول ا. مقادير اختلاف بين ميانگين باندهاى تصوير تلفيق شده با تصوير XS

\begin{tabular}{|c|c|c|c|c|c|c|}
\hline & Brovey & IHS & PCA & WT & Statistical & Statistical_HP \\
\hline IR & -107.876 & -41.6744 & 0.0233 & 0.0704 & 0.4929 & 0.0719 \\
\hline GREEN & -74.3103 & -16.0323 & 1.1504 & -0.0943 & 0.155 & 0.0887 \\
\hline Blue & -68.2708 & -15.1259 & 0.9212 & -0.0522 & 0.1542 & 0.1075 \\
\hline
\end{tabular}

Xدول r. مقادير اختلاف بين انحراف معيار باندهاى تصوير تلفيق شده با تصوير

\begin{tabular}{|c|c|c|c|c|c|c|}
\hline & Brovey & IHS & PCA & WT & Statistical & Statistical_HP \\
\hline IR & -22.321 & 11.9124 & -3.7041 & 4.2767 & 3.737 & 4.5312 \\
\hline GREEN & -40.0505 & 12.3335 & -1.1203 & 2.6916 & 2.8423 & 2.5698 \\
\hline Blue & -36.2978 & 11.5825 & -1.1519 & 3.1704 & 3.4321 & 3.0425 \\
\hline \multicolumn{7}{|l|}{} \\
\hline
\end{tabular}

جدول r. مقادير تفاوت بين ضرايب همبستگى بين باندهاى تصاوير تلفيق شده با ضرايب همبستعى بين باندهاى تصوير XS

\begin{tabular}{|c|c|c|c|c|c|c|}
\hline & Brovey & IHS & PCA & WT & Statistical & Statistical_HP \\
\hline IR_GREEN & 0.36379 & 0.98300 & 0.53903 & 0.17076 & 0.18124 & 0.17869 \\
\hline IR_BLUE & 0.37163 & 0.98166 & 0.54678 & 0.18863 & 0.20099 & 0.19564 \\
\hline GREEN_BLUE & 0.00070 & 0.00214 & -0.00003 & 0.00095 & 0.00013 & 0.00034 \\
\hline
\end{tabular}

جدول f. مقادير ضرايب همبستكى بين باندهاى متناظر در تصاوير تلفيق شده و باندهاى تصوير XS

\begin{tabular}{|c|c|c|c|c|c|c|}
\hline & Brovey & IHS & PCA & WT & Statistical & Statistical_HP \\
\hline IR & 0.895708 & 0.533006 & 0.99714 & 0.909777 & 0.893864 & 0.902895 \\
\hline GREEN & 0.896704 & 0.915506 & 0.75254 & 0.949357 & 0.940747 & 0.943981 \\
\hline BLUE & 0.902926 & 0.918177 & 0.758266 & 0.958738 & 0.953415 & 0.954488 \\
\hline
\end{tabular}

جدول ه. شاخص خطاى RMSE بين باندهاى تصاوير تلفيق شده و باندهاى متناظر تصوير XS

\begin{tabular}{|c|c|c|c|c|c|c|}
\hline & Brovey & IHS & PCA & WT & Statistical & Statistical_HP \\
\hline IR & 107.8757 & 50.11388 & 3.423842 & 11.91314 & 12.15739 & 12.34084 \\
\hline GREEN & 74.31034 & 24.75255 & 34.16043 & 11.86135 & 12.97824 & 12.61299 \\
\hline BLUE & 68.27078 & 23.06722 & 31.10705 & 12.0134 & 13.43459 & 12.81104 \\
\hline
\end{tabular}




\section{بهبود روش آمارى تلفيق تصاوير كَانكور، با ...}

عليرضا آفرى و مسعود ورشوساز روش الماري تلفيق تصناو

جدول 9. شاخص Deviation Index بين باندهاى تصاوير تلفيق شده و باندهاى متناظر تصوير XS

\begin{tabular}{|c|c|c|c|c|c|c|}
\hline & Brovey & IHS & PCA & WT & Statistical & Statistical_HP \\
\hline IR & 0.66404 & 0.31715 & 0.41073 & 0.16656 & 0.30210 & 0.20876 \\
\hline GREEN & 0.66308 & 0.31550 & 0.66088 & 0.13709 & 0.15790 & 0.15164 \\
\hline BLUE & 0.66310 & 0.31540 & 0.57285 & 0.13945 & 0.16181 & 0.15449 \\
\hline
\end{tabular}

در جدول ه ملاحظه مىشود كه مقادير خطاى RMSE براى ستون Statistical و و و

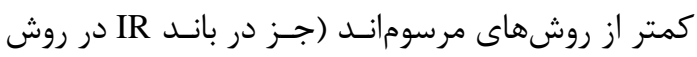

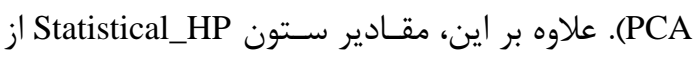
مقادير ستون Statistical، جز در ستون IR كمترند.

\section{DEVIATION INDEX}

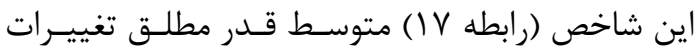

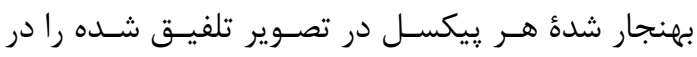
مقايسه با تصوير XS اندازهخيرى مي كند [V] شاخص هرجه كمتر باشد، نشان از كيفيت خوب طيفى تصوير تلفيق شده دارد. اين شاخص بهتر از شاخصهاى ديخر كيفيت طيفى تصوير تلفيق شده را نشان مى دهد.

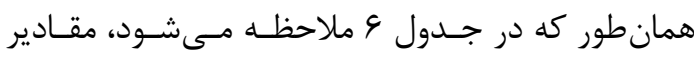
، Statistical_HP بـراى سـتونهـاى Deviation Index WT و Statistical مقادير ستون Statistical_HP نيز كمتر از مقادير ستون Statistical

$$
\mathrm{DI}=\frac{1}{1 \times c} \sum_{i=1}^{1} \sum_{j=1}^{c} \frac{\left|F_{i, j}-M_{i, j}\right|}{M S_{i, j}} \quad \text { رابطه (IV) }
$$

ه- بررسى اندازة هنجرة مــورد اســتفاده در روش كانگُور و همكاران در اين روش آمارى انـدازه ينجـــــاى كـهـ بــراى تعيـين

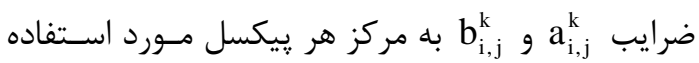
قرار مى گيرد در كيفيت نهايى تصوير تلفيق شده تـأثير

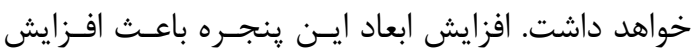

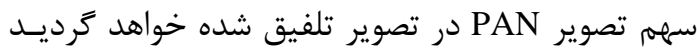

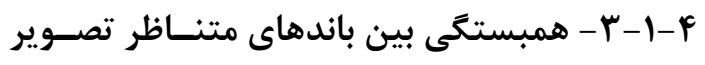
XS

شاخص ديخر براى اندازهزيـرى كيفيـت طيفـى تصـوير تلفيق شده، محاسبؤ ميـزان همبسـتـكى بــين بانـدهاى تصوير تلفيق شده با تصـوير XS اسـت. ايسن مقـدار در

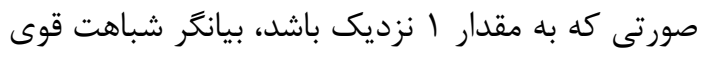
بين باندهاى تصوير تلفيق شـده بـا تصـوير XS خواهـد بود. براى محاسبة اين شاخص نيز رابطـه (ه |) بــهـ كـار

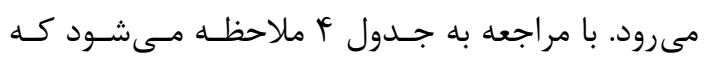

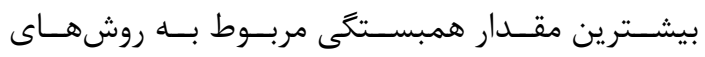
ستون هاى Statistical ،WT، و و Statistical_HP است و مقادير سـتون Statistical_HP بـه مقــادير سـتون WT سـون

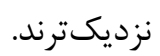

RMSE شاخص خطاى - Fشاخص RMSE بين باندهاى تصوير XS و تصوير تلفيق

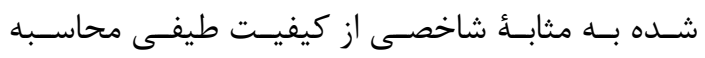
مىشود. اين شاخص مقدار متوسـط تغييـرات ناشـى از يردازش انجام شده در هر ييكسل را اندازهخيرى مى كند

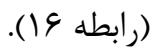

$$
\text { RMSE }=\frac{\sum_{i=1}^{N} \sum_{j=1}^{N} \sqrt{\left(X S_{i, j}-F_{i, j}\right)^{2}}}{N \times N} \text { (1) رابطه (1) }
$$

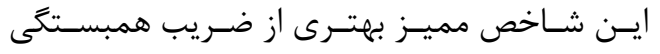

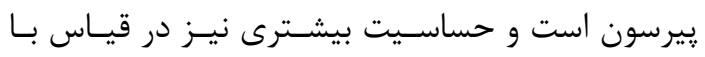

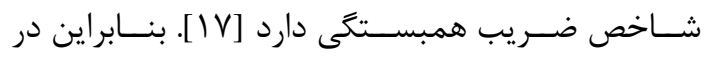
صورتى كه عملكرد دو روش مختلف تلفيـق در مقايسـهـ با ضريب همبستخى ييرسون يكسان باشند، مى تـوان از

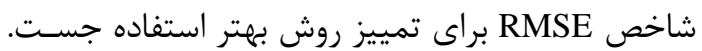


دو تصوير XS و PAN كـه داراى تفسـير طيفى و

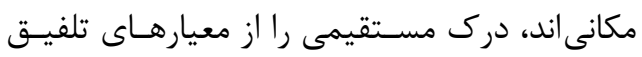
براى كاربر فراهم مى كند. سطحى از امكان در تصميمثيــى بـراى كـاربر در

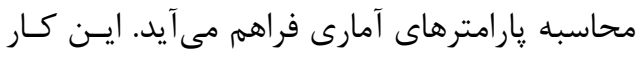

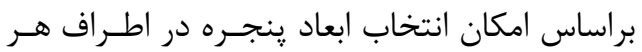

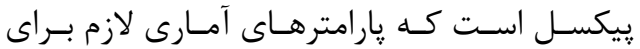
تلفيق از مقادير يِيكسل هاى موجـود در آن ينجــره

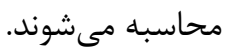
اعمال فيلتر بالآَذر از تأثير منفى اسـتفاده از كـلـ

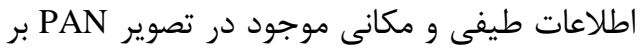
روى كيفيت طيفى تصوير تلفيق شده تا حد زيادى

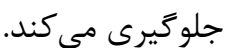

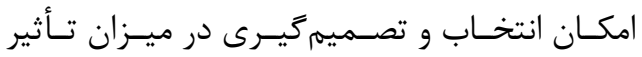
اطلاعات موجود در تصوير PAN بر تصـوير تلفيـق

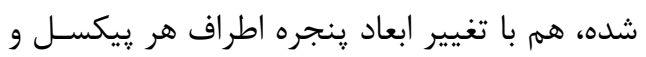

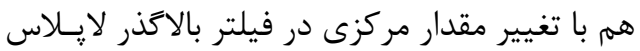

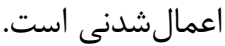
با تغيير انجام شده در معيار دوم ايـن روش آمانـارى

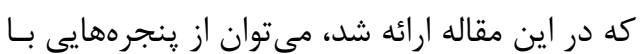

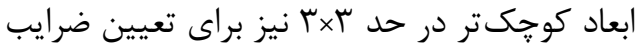

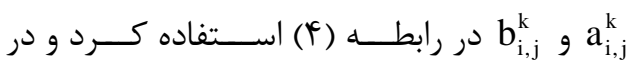

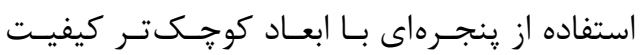
طيفى در تصوير تلفيق شده بهتر حفظ مىشود.

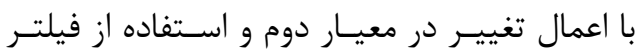
بالاكذر در هنكام استفاده از رنجرههاى داراى ابعاد كو جكتر، تخريب فرايند تلفيق در تعيسين مقـادير

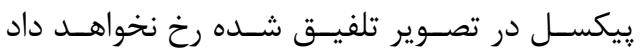

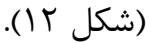
سرعت بردازش و محاسبات، به علت كوجى شدن ابعاد ينجره مورد استفاده افزايش مى يابد.

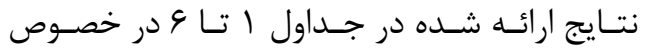

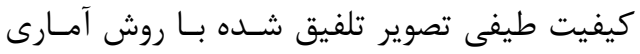
ارائه شده در اين مقاله، نشان مى دهد كه اين روش بـهـ لحـاظ طيفـى داراى كيفيـت مطلـوبى اسـت و و
و تصويرى بارزتر توليد خواهد شد ولى ايـن افـزايش در

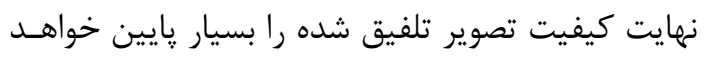
آورد. بنابراين بايستى ابعاد اين ينجره به تناسب انتخاب كردد تا بين كيفيت طيفى و مكـانى در تصـوير تلفيـق باتِ

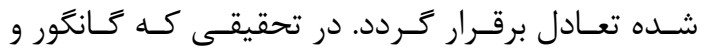

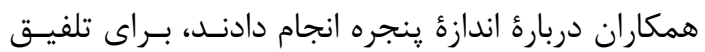

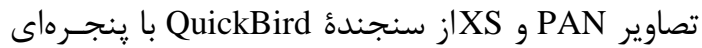
به ابعاد TVXYY بيكسل، تعادل لازم در كيفيت هندسى

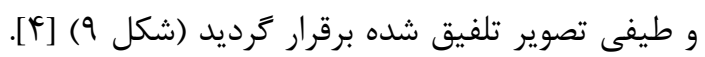
اين در حالى است كه با استفاده از معيار دوم ارائه شده كرداد

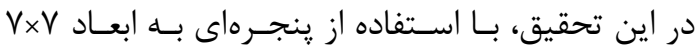

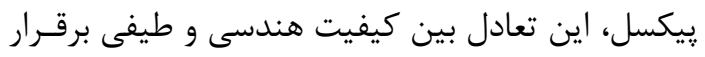

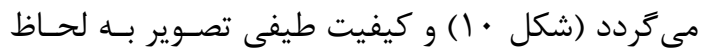

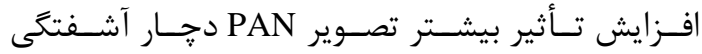

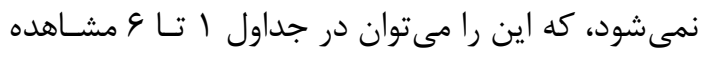

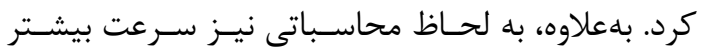

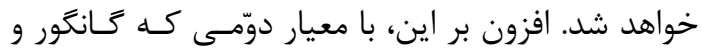

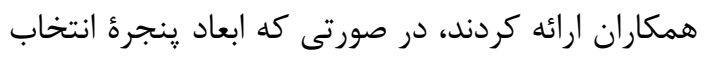

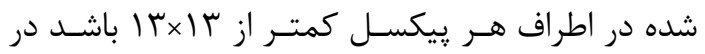
بخشهايى از تصوير كه بازتابش شديدى دارند، مقـادير

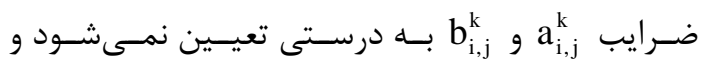
تخريب كامل بيكسل ها در آن بخش از تصـوير صـورت

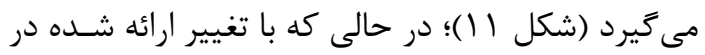

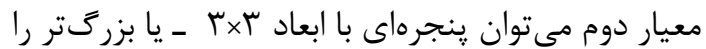

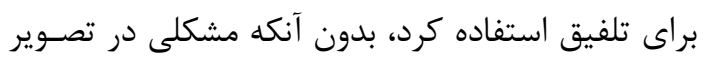
تلفيق شده ايجاد گردد (شكل r I).

\section{9- نتيجه كيرى و ييشنهاد}

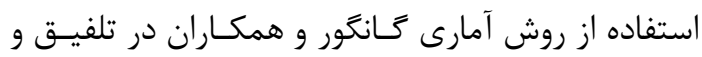

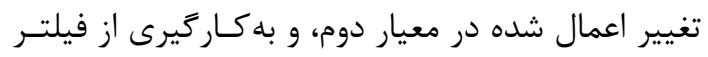

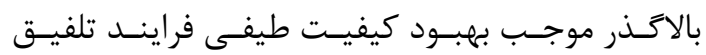

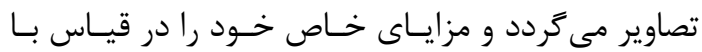

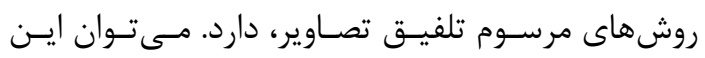
بهبود و مزايا را مواردى از اين دست دانست:

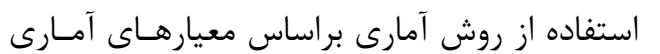


PAN و و نيز بين تصـاوير ســنجندههـاى مختلـف

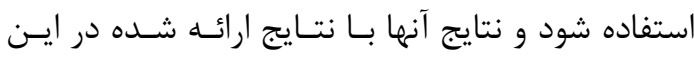
تحقيق مقايسه كردد. بهعلاوه، يِيشنهاد مىشـود كــه از

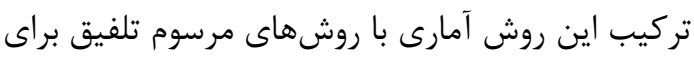
بهبود كيفيت روشهاى متداول استفاده گردد.
مى تواند به عنــوان جـايـزينى معـادل بــراى روش تلفيق با تبديل موجك نيز مورد استفاده قرار كيرد.

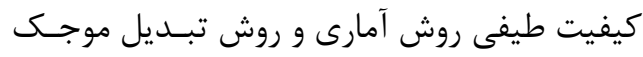
بسيار بهتر از روشهاى مرسوم تلفيق است.

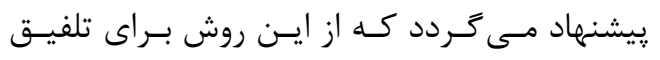
تصاوير با نسبت هاى متفاوت بين قدرت تفكيك تصـوير

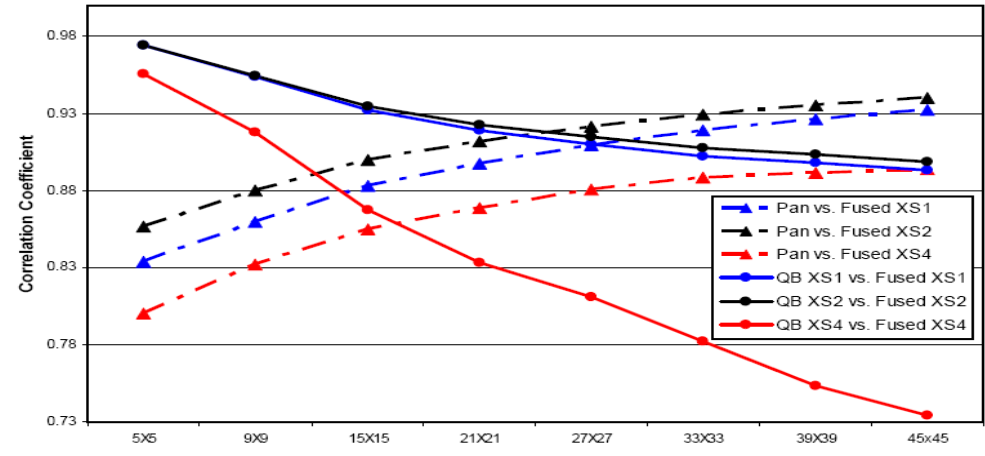

شكل 9. ضريب همبستغى به صورت تابعى از ابعاد ينجره (بركرفته از [CF)

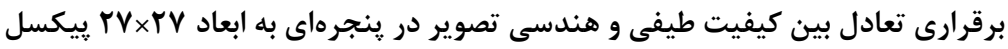

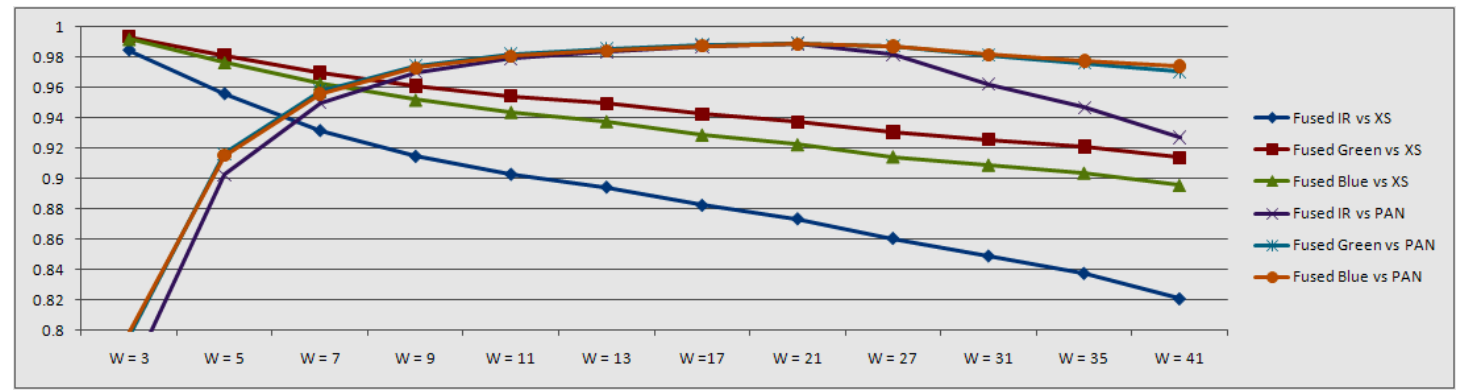

شكل •1. ضريب همبستكى به صورت تابعى از ابعاد ينجره

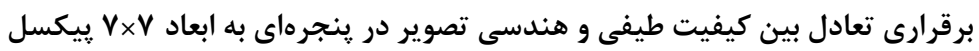

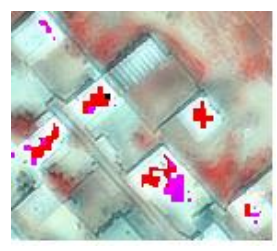

Win size $=3 \times 3$

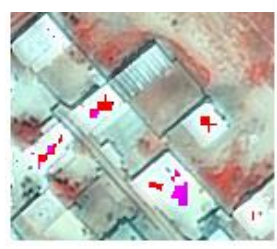

Win size $=5 \times 5$

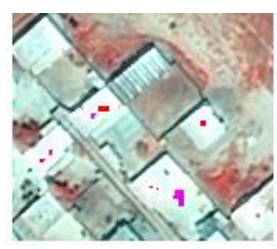

Win size $=7 \times 7$

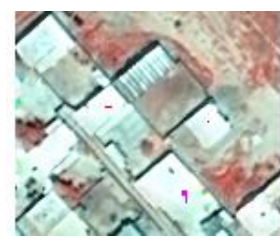

Win size $=9 \times 9$

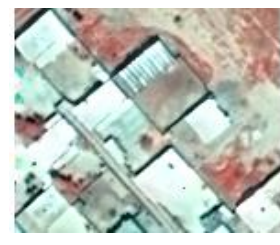

Win size $=11 \times 11$

شكل Iا. تأثير ابعاد ينجره در كيفيت تصوير تلفيق شده با روش كانغكور و همكاران

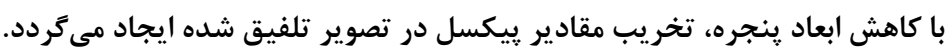




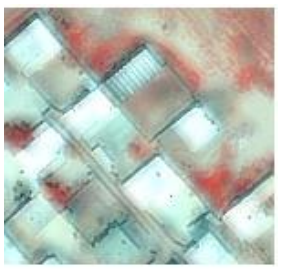

Win size $=3 \times 3$

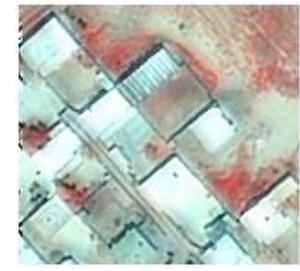

Win size $=5 \times 5$

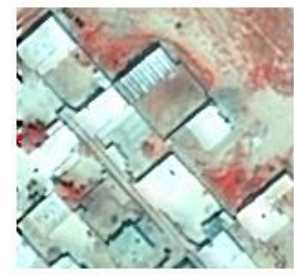

Statistical $=7 \times 7$

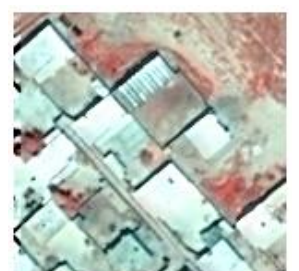

Win size $=9 \times 9$

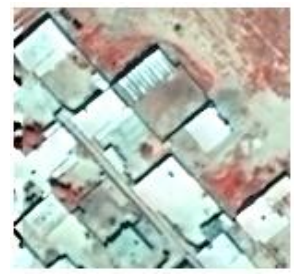

Win size $=11 \times 11$

$$
\begin{aligned}
& \text { شكل rا. تأثير ابعاد ينجره در كيفيت تصوير تلفيق شده با روش ارائه شده در اين مقاله }
\end{aligned}
$$

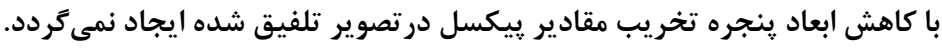

$$
\text { - منابع }
$$

[1] Wald, L., Ranchin T. and Mangolini M., 1997. Fusion of Satellite Images of Different Spatial Resolutions: Assessing the Quality of Resulting images. Photogrammetric Engineering and Remote Sensing, 63(6), 691-699.

[2] Ranchin, T., Aiazzi, B., Alparone, L., Baronti, S. and Wald, L., 2003. Image Fusion - ARSIS Concept and Some Successful Implementation Schemes. ISPRS Journal of Photogrammetry and Remote Sensing, 58, 4-18.

[3] Pohl, C. and Van Genderen, J.L., 1998. Multisensor Image Fusion in Remote Sensing: Concepts, Methods and Applications. International Journal of Remote Sensing, 19 (5), 823-854.

[4] Gungor, O. and Shan, J., 2005. A Statistical Approach To Multiresolution Image Fusion. ASPRS Pecora 16 Global Priorities in Land Remote Sensing, Sioux Falls, South Dakota.

[5] Park, J.H. and Kang, M.G., 2004. Spatially Adaptive Multi-resolution Multispectral Image Fusion. International Journal of Remote Sensing, 25(23), 5491-5508.

[6] Shamshad, A., Wan Hussin, W.M.A. and Mohd Sanusi, S.A., 2004. Comparison of Different Data Fusion Approaches for Surface Features Extraction Using Quickbird Images. Proceedings GISIDEAS 2004, Hanoi, Vietnam.
[7] Schowengerdt, R.A., 1980. Reconstruction of Multispatial, Multispectral Image Data Using Spatial Frequency Content. Photogrammetric Engineering \& Remote Sensing, 46(10), 1325-1334.

[8] Gungor, O. and Shan, J., 2004. Evaluation of Satellite Image Fusion Using Wavelet Transform. XX th ISPRS Congress, Istanbul, Turkey.

[9] Chavez, P.S., Sides, S.C. and Anderson, J.A., 1991. Comparison of Three Different Methods to Merge Multiresolution and Multispectral Data: Landsat TM and SPOT Panchromatic. Photogrammetric Engineering \& Remote Sensing, 57(3), 295-303.

[10] Van Der Meer, F., 1997. What does Multisensor Image Fusion Add in Terms of Information Content for Visual Interpretation? International Journal of Remote Sensing, 18(2), 445-452.

[11] Yocky, D.A., 1995. Image Merging and Data Fusion by Means of the Twodimensional Wavelet Transform. Journal of the Optical Society of America, 12(9), 1834-1845.

[12]Zhang, Y., 2002. Problems in the Fusion of Commercial Highresolution Satellite Images as well as Landsat 7 Images and Initial Solutions. International Archives of Photogrammetry and Remote Sensing, 34(4), SDH Joint International Symposium on GeoSpatial Theory, Processing and Applications, Ottawa, Canada, July 8-12. 
بهبود روش آمارى تلفيق تصاوير كَانكَور، با ...

[13] Nunez, J., Otazu, X., Fors, O., Prades A., Pala, V. and Arbiol, R., 1999. Multiresolution-based Image Fusion with Additive Wavelet Decomposition. IEEE transactions on Geoscience and Remote Sensing, 37(3), 1204-1211.

[14]Lemeshewsky, G.P., 2002. Multispectral Image Sharpening Using a Shift-invariant Wavelet Transform and Adaptive Processing of Multiresolution Edges. Visual Information Processing XI (Z. Rahman and R.A. Schowengerdt, editors). Proceedings of SPIE, 4736.

[15]Ute G.G., Pushkar S.P. and Derrold W.H., 2008. Optimizing the High-Pass Filter Addition Technique for Image Fusion. Photogrammetric engineering \& Remote Sensing, 74(1), 1107-1118.

[16]Zhou J., Civco D.L. and Silander J.,A., 1998. A Wavelet Transform Method to
Merge Landsat TM and SPOT Panchromatic Data. International Journal of Remote Sensing, 19(4), 743-757.

[17] Pradhan, P., R. King, N.H.Y. and Holcomb, D.W., 2006. The Effect of Decomposition Levels in Wavelet-based Fusion for Multiresolution and Multi-sensor Images. IEEE Transactions on Geoscience and Remote Sensing, 1.44(12), No. 12, 3674-3686.

[18] Shi W., Zhu C., Tian, Y. and Nichol J., 2005. Fusing IKONOS Images based on Four-band Wavelet Transformation Method. International Journal of Applied Earth Observation and Geoinformation. 6(3-4), 241-251.

[19] Costantini M., Farina A. and Zirilli F., 1997. The Fusion of Different Resolution SAR Images. Proceedings of the IEEE, 85(1), 139-146. 


\title{
Improvement of Gungor Image Fusion Technique Using a High Pass Filter
}

\author{
Afari A. $*^{1}$, Varshosaz M. ${ }^{2}$ \\ 1- Senior Lecturer, Babol University of Technology \\ 2- Assistant Prof., K.N. Toosi University of Tehonology
}

\begin{abstract}
Statistical methods are among image fusion techniques which use statistical measures, global or local, in order to decide how and where the fusion is performed. One of the most recent techniques of such giving good radiometric results is that developed by Gungor et al. which is based on the use of local parameters. Aiming to improve their results, this adds a high pass filter to their process. Tests carried out showed that the use of such a hybrid technique, in addition to improve the radiometric quality of the fused image, requires smaller processing windows. Also, it incorporates more of the spatial information from the panchromatic image without any loss in the radiometric quality of the fused image. Moreover, other experiments indicated that this approach shows great improvements compared to those obtained by HIS, Brovey and PCA while having equivalent results as those obtained by a Wavelet Transform.
\end{abstract}

Keywords: Image fusion, Statistical techniques, High pass filter.

Correspondence Address: Mazandaran Province, Babol, Babol Noshirvani University of Technology. Tell: 09122894189 Email: afary@nit.ac.ir 